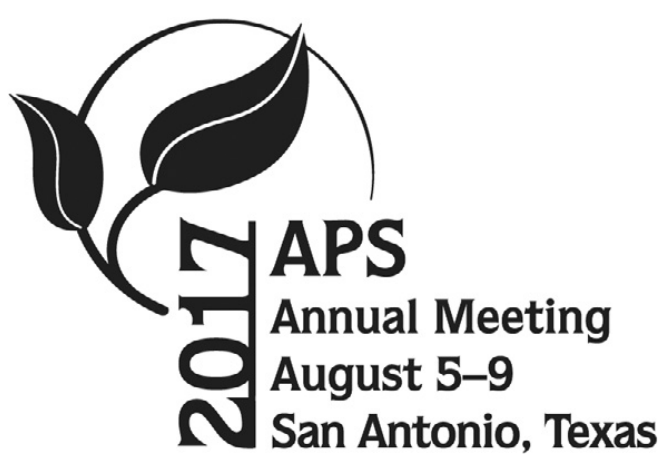

\title{
2017 APS Annual Meeting Abstracts of Special Session Presentations
}

The abstracts are published for citation purposes. They were not reviewed by the Phytopathology Editorial Board and were not edited by the APS editorial staff. Please send questions or comments to aps@scisoc.org.

https://doi.org/10.1094/PHYTO-107-12-S5.143

(C) 2017 The American Phytopathological Society

The P6 effector protein of Cauliflower mosaic virus: A masterswitch in the virus infection cycle J. SCHOELZ (1), M. Adhab (2), C. A. Angel (3), R. S. Nelson (4), (1) University of Missouri, Columbia, MO, USA; (2) University of MissouriColumbia, Columbia, MO, USA; (3) Cenicafe - Colombia, Manizales, COLOMBIA; (4) Samuel Roberts Noble Foundation, Inc., Ardmore, OK, USA

The $\mathrm{P} 6$ protein of Cauliflower mosaic virus (CaMV) is a $66 \mathrm{kDa}$ protein that forms the matrix for the electron dense, amorphous inclusion bodies (IBs) that accumulate in the cytoplasm. Early electron micrographs revealed that host ribosomes were found in association with the P6 IBs, and nearly all of the icosahedral CaMV virions accumulate and are retained within the P6 IBs. Subsequent studies provided an explanation for the association of P6 IBs and host ribosomes; the P6 protein physically interacts with host ribosomes to reprogram them for expression of all CaMV proteins on the polycistronic $35 \mathrm{~S}$ mRNA, a process called translational transactivation. For many years, translational transactivation was thought to be the primary function of the P6 protein. However, several recent studies have expanded our understanding of the true impact of the P6 protein on CaMV infections, as the P6 protein has been shown to mediate intracellular movement, elicit defenses in hypersensitive hosts or symptoms in susceptible hosts, modulate SA- and JA-mediated host defenses, and suppress antiviral gene silencing. Furthermore, the P6 protein interacts with at least 14 host and virus proteins, of which distinct subsets are associated with individual functions. This presentation will illustrate how newly identified virus-host protein interactome maps complemented with subcellular localization studies can be used to further define the role of the P6 protein in the CaMV disease cycle.

The tobamovirus 126-kDa protein: A multifunctional, multi-interacting, and evolving protein that influences disease R. S. NELSON (1), A. Ibrahim (1), K. Cooper (1), J. E. Schoelz (2), (1) Samuel Roberts Noble Foundation, Inc., Ardmore, OK, USA; (2) University of Missouri, Columbia, MO, USA

Tobamoviruses encode a limited suite of proteins that often interact with additional host or viral proteins to support virus replication and movement. One tobamovirus protein, the $126 \mathrm{kDa}$ protein of Tobacco mosaic virus, supports both virus accumulation and movement (intra- and inter-cellular). Full understanding of how this protein supports these activities remains a mystery. Through genetic and molecular methods we studied the interaction of the $126 \mathrm{kDa}$ protein with host proteins to determine how these interactions influence the infection process. We also determined that an ortholog of this protein from another tobamovirus, the $125 \mathrm{kDa}$ protein from Turnip vein clearing virus, interacts mostly with a different group of host proteins than does the $126 \mathrm{kDa}$ protein. For example, the interaction of the 126 and $125 \mathrm{kDa}$ proteins with various host cytoskeletal and vacuole/prevacuole-associated proteins differs, likely reflecting differences in the intracellular location of the two proteins and the requirements for intercellular spread of the encoding tobamoviruses. Based on this work, the function of the two proteins during virus spread will be proposed. The proposal demonstrates not only the multiinteracting and -functional nature of these orthologs, but their evolution to different activities. Conclusions from this work will highlight the promising and less promising pathways for translating this information into the production of virus-resistant plants.

The p33 protein of Citrus tristeza virus: A conundrum of multiple functions S. Y. FOLIMONOVA, University of Florida, Gainesville, FL, USA

Citrus tristeza virus (CTV), the most economically important viral pathogen of citrus, encodes a unique protein, p33. Research conducted over the recent years showed that this protein plays multiple important roles in viral pathogenesis. It was found that while $\mathrm{p} 33$ is dispensable for infection of a number of citrus varieties, it is required for systemic infection of a few others. Furthermore, p33 is one of the key viral factors mediating virus ability to exclude superinfection with the same or closely related virus. The characterization of p33 demonstrated that it is a self-interacting integral membrane protein, and its membrane localization is important for virus ability to infect an extended host range. In the infected cells, p33 shows plasmodesmata localization and forms extracellular tubules, which are the characteristic features found for a number of movement proteins of other plants viruses. Although p33 is not conserved among other closteroviruses, a few members of the genus Closterovirus encode proteins of $\sim 30 \mathrm{kDa}$ whose corresponding genes are situated at the same genomic position as that of the CTV p33 gene. While primary sequences of those proteins do not share significant homology, some of their characteristics along with their secondary structures show some similarities. Further research is required for a better understanding of the functions that these proteins play in virus infection and the overall genome complexity of closteroviruses. 
Rhabdoviruses infect a wide range of hosts, and members of this group include viruses that infect humans, terrestrial animals/vertebrates, fish, arthropods, and plants. The genomes of the plant-adapted viruses are organized generally into seven open reading frames with the gene order 3'-N-X-PY-M-G-L-5', which encodes the nucleocapsid, phospho, movement, matrix, glyco, and RNA-dependent RNA polymerase proteins, respectively, except for $\mathrm{X}$, which is of unknown function. In addition to its structural role in virion formation, the M protein of Potato yellow dwarf virus (PYDV) is capable of inducing the intranuclear accumulation of the inner nuclear membranes (INM) in transfected cells. The M protein also interacts with the nuclear import and export receptors Importin-alpha and Exportin 1, suggesting a role for $\mathrm{M}$ in transport of condensed nucleocapsids from the nucleus. Interestingly, the ability to remodel the INM is conferred by the P, but not M, protein of coffee ringspot dichorhavirus, demonstrating that functional domains within rhabdoviral proteins are portable. This variation likely contributes to the finding that protein interaction and localization maps (PILMs) for each virus are unique. How these variations in protein sequence contribute to the manner by which these viruses remodel the architecture of plant nuclei will be discussed.

Dissecting the mechanism of Potato virus $X$ insertion into plasmodesmata

Y. Lu (1), D. Burnett (1), M. Zabrady (2), J. TILSNER (1,3), (1) James Hutton Institute, Dundee, UNITED KINGDOM; (2) University of St Andrews, St Andrews, UNITED KINGDOM; (3) University of St. Andrews, St. Andrews, UNITED KINGDOM

Potato virus $\mathrm{X}$ requires four virus-encoded proteins, the triple gene block (TGB1, TGB2 and TGB3) of movement proteins and the capsid protein (CP), for intercellular transport and spread throughout the host plant. Cell biological and biochemical studies of these four proteins have led to a model where the transmembrane proteins TGB2/3 target viral replication complexes to plasmodesmata and partially encapsidated progeny virus genomes are then directly inserted into the intercellular channels. The multifunctional TGB1 protein, which also acts as an RNA helicase, a suppressor of RNA silencing and a translational activator, seems to play a crucial role in inserting PVX into plasmodesmata. I will present a new live-cell RNA imaging system that is sensitive enough to allow detection of PVX RNA within the plasmodesmata, and our attempts to dissect the molecular mechanism by which TGB1 facilitates virus movement.

\section{Geminivirus C4 proteins: Divergent functions}

C. M. DEOM, University of Georgia, Athens, GA, USA

Four genera of geminiviruses contain a small open reading frame nested in the $C 1$ (replication-initiator protein) gene that encodes for, or has the potentially to encode for, a $\sim 10 \mathrm{kDa}$ protein designated $\mathrm{C} 4$ (AC4 in bipartite geminiviruses). The Beet curly top virus $\mathrm{C} 4$ protein is the best studied and is well suited for investigation of protein function. Ectopic expression of the BCTV C4 protein leads to a severe developmental phenotype characterized by hyperplasia that mimics symptoms induced by BCTV. The C4 protein interacts with seven of ten members of the Arabidopsis thaliana SHAGGY-like protein kinase (AtSK) gene family. AtSKs are homologues of the glycogen synthase kinase 3 family of serine/threonine kinases in animals and play key regulatory roles in a wide range of cellular processes. The C4/AtSK interactions require phosphorylation of C4 serine residue 49 and an active catalytic site in AtSKs. Disruption of a C4 N-myristoylation motif, which is required to localize $\mathrm{C} 4$ to the plasma membrane, results in nonfunctional C4 that still binds AtSKs. Bikinin, a specific inhibitor of the seven AtSKs with which C4 interacts, also induces hyperplasia in Arabidopsis mimicking C4-induced hyperplasia. The BCTV C4 protein functions by inhibiting members of the AtSK gene family that have evolved to address diverse plant-specific functions. As a group, $\mathrm{C} 4(\mathrm{AC} 4)$ proteins are multi-functional, having roles in symptom severity, movement, and/or posttranscriptional gene silencing.

\section{Lose the effector or die tryin': Novel quantitative resistance loci for bacterial blight}

A. I. HUERTA (1), E. Delorean (1), A. Bossa-Castro (1), C. Raghavan (2), R. Corral (1), V. M. Verdier (3), H. Leung (4), J. E. Leach (1), (1) Colorado State University, Fort Collins, CO, USA; (2) International Rice Research Institute, Metro Manila 1301, PHILIPPINES; (3) IRD, Cirad, Univ Montpellier, IPME, Montpellier, FRANCE; (4) Intl Rice Research Inst, Metro Manila, PHILIPPINES

Bacterial blight (BB), caused by Xanthomonas oryzae pv. oryzae (Xoo), is the single most destructive bacterial disease of rice. The optimal agronomic practice to manage the disease is deployment of resistant varieties. However, effective and durable disease resistance for BB is a continuous challenge due to the pathogen's evolution and adaptation on cultivated varieties. Key to Xoo pathogenicity and virulence are Transcription Activator-Like (TAL) effectors, which activate expression of host susceptibility genes. TAL effectors differently contribute to a strain's virulence, and some are essential to pathogen fitness. We hypothesize that effective and durable disease resistance is attainable by targeting important virulence factors in the bacterium. To test this hypothesis we took advantage of the indica Multi-Parent Advanced Generation Inter-Cross (MAGIC) inbred lines and screened them for resistance against Xoo strains PXO99A and PXO99A carrying the virulence factor TAL7b (+TAL7b). Transgressive segregation for resistance in the MAGIC lines was observed to both PXO99A and PXO99A + TAL7b, suggesting the presence of resistance for BB. Genome-wide association and interval mapping analysis revealed 13-disease resistance QTL, six specific to PXO99A +TAL7B and seven to PXO99A. The top ranking predicted gene target for TAL7b correlated to a QTL on chromosome 8. Altogether, our data suggest that the TAL 7b target is a disease susceptibility gene that contributes to Xoo fitness in rice and that the resistance locus identified may harbor polymorphisms in the TAL7b gene target, disabling activation of the susceptibility gene. Future research will focus on the mechanism underlying this novel resistance phenotype.

How does plant immunity restrict bacterial virulence?

B. KVITKO, A. Lovelace, University of Georgia, Athens, GA, USA

Plants present cohorts of pattern recognition receptors that are able to detect "non-self" microbe-associated molecular patterns (MAMPs) such as bacterial flagellin. In Arabidopsis thaliana the bacterial flagellin epitope flg22 is a potent elicitor of the Pattern-Triggered-Immunity (PTI) response. The introduction of the pathogen Pseudomonas syringae pv. tomato DC3000 (Pto) into PTI-activated leaves results in non-virulent stasis during which Pto fails to deliver type III secretion system effectors (T3Es), does not multiply, and fails to cause symptoms. The molecular mechanisms by which PTIassociated immune outputs restrict bacterial virulence are not well understood. To gain a clearer picture of the conditions Pto experiences during PTI, we conducted an in situ time-course transcriptomics analysis. Exposure to PTI resulted in reduced expression of multiple virulence factors. Conversely, immune exposure was associated with the increased relative expression of motility genes and specific nutrient uptake systems. We hypothesize that nutritional restriction may represent a key mechanism of PTI. In addition, we have found that co-infiltration of Pto with $1 \%$ tryptone was sufficient to partially alleviate non-virulent stasis even in leaves with fully established PTI. Co-infiltration with tryptone was observed to restore T3E translocation in PTI induced tissue by both HR assays and using the Cya adenylate cyclase T3E translocation assay. Activity-guided fractionation linked the T3E 
translocation restoration activity to a small peptide. These observations are important clues towards a mechanistic understanding of the highly effective innate immune defenses of plants.

Managing Phomopsis stem canker of sunflower using host resistance

F. M. MATHEW (1), T. Olson (1), L. Marek (2), (1) South Dakota State University, Brookings, SD, USA; (2) Iowa State University, Ames, IA, USA

Phomopsis stem canker of sunflower (Helianthus annuus) is a priority disease of the sunflower farmers in the United States. The disease is predominantly caused by Diaporthe helianthi and Diaporthe gulyae. The objective of this study was to use quantitative polymerase chain reaction (qPCR) assays to screen sunflower genotypes for resistance to D. helianthi and D. gulyae. Fifty-four genotypes that exhibited potential resistance to Phomopsis stem canker were selected from 288 Plant Introductions screened under natural disease pressure in a field trial. Sunflower cultivar 'HA 288' (PI 552934) was used as the susceptible check for the study. Each of the sunflower genotypes were inoculated with a Diaporthe-infested mycelial plug of an aggressive isolate of $D$. helianthi or D. gulyae in separate experiments under greenhouse conditions. At 14 days after inoculation, the genotypes were rated for disease. Additionally, the amount of pathogen DNA in the inoculated plants was determined using qPCR assays specific to the two pathogens. For both the pathogens, the susceptible genotypes had significantly higher disease severity and amount of pathogen DNA as compared to the resistant accessions. The resistant genotypes identified in this study will be useful for developing commercial sunflower hybrids with resistance to $D$. helianthi and D. gulyae.

Evolving phenolic roles in host defense: The cases of 'Candidatus Liberibacter solanacearum' potato infections and that of grapevine pathogens C. M. WALLIS (1), S. A. Lee (1), E. E. Rogers (2), E. R. Galarneau (3), K. Baumgartner (4), (1) USDA ARS, Parlier, CA, USA; (2) USDA ARS FDWSRU, Fort Detrick, MD, USA; (3) University of California Davis, Davis, CA, USA; (4) USDA ARS, Davis, CA, USA

Upon infection, plants produce phenolic compounds presumably to defend against pathogens and assist in tissue repair. However, phenolic production in response to infection by 'Candidatus Liberibacter solanacearum' (Lso), causal agent of zebra chip disease, was linked directly to increased browning symptoms in freshly-sliced potato tubers. Furthermore, potato breeding lines deemed "tolerant" of Lso infections, due to lack of browning symptom development, accumulated lower phenolic levels following infection compared to susceptible varieties, suggesting the mechanism of tolerance was a lack of large-scale induced phenolic production as a host response. Likewise, there is building evidence that Xylella fastidiosa, causal agent of Pierce's disease of grapevine, also might benefit from host phenolic production, as in culture this bacteria appears to consume certain phenolic compounds and grows better when phenolics are present at physiological levels. Finally, recent experiments observed that grapevine fungal pathogens deemed aggressive were able to consume or otherwise eliminate certain phenolics from media whereas less aggressive pathogens could not. In sum, phenolics have more complicated roles in plant-pathogen interactions than previously thought and, in some cases, phenolics may benefit pathogens more than plant hosts.

\section{Losses, regrets and expectations: An overview of attaching value to disease management decisions} N. MCROBERTS, University of California-Davis, Davis, CA, USA

While not being entirely neglected by plant pathologists, economics has not so far been incorporated into our discipline as comprehensively as it has in cognate disciplines such as weed science and entomology; there is no equivalent in plant pathology of the Journal of Economic Entomology. At an applied level there is, of course, a long-standing interest in comparing different crop mangement approaches using cot-benefit and cost effectiveness approaches. However, if we consider the concept of ecnomics in its wider sense as the study of decision making under constraints it is clear that a more general economic theory of plant disease management has been slow to develop. We consider recent interest in decision theory, information theory and game theory within plant pathology and review the prospects for these concepts to contribute to the development of a more clearly defined economic framework for plant disease management.

Risk analysis and economic optimization of late blight management tactics

I. M. SMALL (1), Y. Liu (2), M. Langemeier (3), L. Joseph (4), W. E. Fry (4), (1) University of Florida, Quincy, FL, USA; (2) Dept. of Agriculture, Eastern Kentucky University, Richmond, KY, USA; (3) Dept. of Ag. Economics, Purdue University, West Lafayette, IN, USA; (4) Cornell University, Ithaca, NY, USA

Calendar-based fungicide application schedules are often employed to manage late blight regardless of existing disease severity, disease-resistance level of the potato cultivar, or prevailing weather. Such strategies may not be economically or environmentally efficient. BlightPro decision support system (DSS)-based fungicide application schedules are influenced by prevailing weather and host resistance. Objectives of this study were to assess the economic value of information created by the DSS and to optimize forecasting rules in the DSS for disease suppression and profitability. Three fungicide scheduling strategies were evaluated: calendar-based strategy, DSS-based strategy, and unsprayed. Using results from simulation experiments for several locations in the United States, we constructed distributions of the net return to all costs excluding fungicide cost and application cost (net return per acre) for calendar-based and DSS-based strategies at each location. These distributions were then compared using risk management methods: stochastic dominance with respect to a function and stochastic efficiency with respect to a function. The DSS-based strategy was identified as the most effective approach in terms of disease suppression, net return per acre, and risk-adjusted net return. The value of the information created by the DSS varied by cultivar resistance, producers' risk-aversion level, and production location.

Networked real time disease risk evaluation: A cost-effective approach to disease management O. CARISSE (1), H. Van Der Heyden (2), (1) Agric \& Agri-Food Canada, Saint-Jean-sur-Richelieu, QC, CANADA; (2) Compagnie de recherche Phytodata, Sherrington, QC, CANADA

A continuing challenge in plant pathology is to develop cost-effective disease management strategies. There are however only few studies on cost effectiveness of crop disease control tactics and strategies. In eastern Canada, scouting and advisory programs were implemented in the mid-80s and continue to support growers in their disease management decisions. Since the initiation of scouting programs, several new control methods and approach were adopted by growers and information on disease, yield, weather, cultural practices, and fungicide usage recorded. This offers a unique opportunity to study the long-term cost effectiveness of proposed/adopted control methods. During this talk, onion leaf blight (OLB) (Botrytis squamosa) management will be used as a case study. From mid-80 to mid-90s decision making regarding fungicide application was based on scouting data and action thresholds, follow by addition of weather-based forecast to identify at risk for sporulation and infection period. Starting in 2000, DNA-based real time information on airborne inoculum and on fungicide resistance was gradually included as another tool to time fungicide applications. Currently, OLB is managed from information collected at the field/farm and regional scale (network). Temporal variation in OLB since 1986 is characterized by a steady reduction in disease severity and in fungicide usage (38\%). By itself these observations support the idea that this program is cost effective, however, cost 
effectiveness is more than considering money saving, and should include long term effect on environmental and human health, improve grower's confidence in disease management decision making, preservation of market, and consumer trust.

Cost-benefit analysis of integrated management strategies for Fusarium head blight of wheat

P. A. PAUL, J. Salgado, L. V. Madden, Ohio State Univ, Ohio Agricultural Research and Development Center, Dept of Plant Pathology, Wooster, OH, USA

Fusarium head blight (FHB), caused by Fusarium graminearum, negatively affects wheat by causing shriveled and lightweight kernels, reducing grain yield and test weight (weight per unit volume), and contaminating grain with mycotoxins such as deoxynivalenol (DON). Yield loss and price discounts due to test weight below and Fusarium damaged kernels and DON above grain quality thresholds reduce the net cash income received by producers. Since no fungicide is $100 \%$ effective against, and no cultivar is immune to, FHB, yield and quality losses may still occur even when the best management practices are implemented. Variations in disease intensity, fungicide efficacy, grain prices, production costs, and grain yield and quality responses often make FHB management decision-making a challenging task. When disease and toxin levels are low, planting a resistant but low-yielding cultivar may come at the expense of grain yield, and using a fungicide may result in producers incurring application costs without seeing the benefits in terms of higher grain yield and quality. On the other hand, failure to use effective integrated management strategies when disease levels are high results in substantial grain yield and quality losses. Using data from two decades of research, we will demonstrate and discuss the use of meta-analysis as a tool for quantifying the probability of profitable FHB management for a range of grain yield and disease responses, grain prices, and management costs.

Impact Network Analysis: A framework for evaluating the effects of technologies through linked socioeconomic and biophysical networks K. A. GARRETT, University of Florida, Gainesville, FL, USA

Decision-making about disease management is ultimately driven by money. Farmers decide what management strategies to adopt, and sponsors decide what research and development projects to support, based on their financial constraints. Understanding how to optimize the effects of research and data collection typically requires integration across three general types of system components: (a) the type and quality of information and other technologies, (b) socioeconomic networks that determine communication and influence about technology use, such as networks of farmers, and (c) biophysical networks where decisions about use of technologies determine epidemiological outcomes. Impact Network Analysis is a framework to integrate these three components, providing a systems perspective to evaluate potential outcomes from research and development investments. Impact Network Analyses can also be used to assess the resilience of a system to new perturbations, such as climate change or the introduction of a new pathogen. Network analysis, as compared to more aggregated models, allows for consideration of the role of geographic and social structures on the likelihood of success of technological innovations. Applications of Impact Network Analysis will be illustrated for disease management in the field, in seed systems, and in postharvest food chains. Experimental choice games will also be introduced, in the context of evaluating willingness to pay for new technologies.

Disease control: A seed company perspective

J. W. PITKIN PHD, Monsanto, Chesterfield, MO, USA

There are three main modes of delivery for disease control solutions by private agricultural companies: in the seed (disease traits) on the seed (seed treatments) or over the top (fungicides). The desire to combat diseases must be balanced by the overall profitability of any disease control system for the farmer customer. The most important disease to our customers when making seed choices is often the disease the farmer has struggled to control over the last season or two on his or her farm. Given that disease pressure is regional and periodic, all of these factors must be considered when determining the value of "in the bag" seed solutions for disease control in row crops.

PacC-dependent differential regulation of nutrition-associated genes for adaptation to alkalinized host cells by Magnaporthe oryzae Y. L. PENG, China Agri. Univ., Beijing, CHINA

Plant cell alkalinization is a widely recognized immune response to attack by pathogens. Here, we report how the blast fungus Magnaporthe oryzae responds to $\mathrm{pH}$ changes during infection. We identified nine alkaline $\mathrm{pH}$-sensitive mutants which were all similarly impaired in virulence. Strikingly, disrupted genes in the mutants were all involved in the $\mathrm{PacC} \mathrm{pH}$ regulatory pathway. Interestingly, when invasive hyphae started proliferation, host cells became alkalinized, and the PacC transcription factor simultaneously nuclear localized and directly regulated differential expression of $\sim 1930$ genes, including many involved in acquisition and utilization of nutrients. M. oryzae PacC has two functional forms, a truncated activator, PacC ${ }^{222}$, and a fulllength repressor, $\mathrm{PacC}^{559}$, which localized to nuclei at $\mathrm{pH}>7.2$ to activate genes required for virulence and represses genes associated with other developments during infection, respectively. Establishment of the blast disease therefore requires PacC-dependent differential regulation of nutritionrelated genes for adaptation to host cellular $\mathrm{pH}$ alkalinization.

The role of barberry in virulence variation and epidemics of wheat stripe rust in China

Z. KANG, J. Zhao, Y. Tian, Y. Zhao, Q. Li, G. Zhan, L. Huang, Northwest A\&F University, Yangling, Shaanxi, CHINA

Wheat stripe rust caused by Puccinia striiformis f. sp. tritici (Pst), is a destructive disease of wheat worldwide. Virulence variation of the pathogen contributes to produce new races, resulting in breakdown of wheat resistance, and causing subsequent epidemics of the disease. Recently, sexual cycle of Pst was found based on identification of barberry (Berberis) as alternate host, making it possible to understand roles of sexual reproduction in virulence variation of $P s t$ and alternate hosts in epidemics of the disease. In China, our investigations found that many various barberry species widely distributed in epidemic areas of the disease and most of them were alternate hosts for Pst based on artificial inoculation. More importantly, a large number of $P s t$ samples were recovered in succession from naturally infected barberry species. Some were known races including current predominant races and the other were new races based on virulence tests. Barberry-derived Pst samples were originated from the western China in which susceptible barberry widely distributed in quantity or species and sexual reproduction of $P s t$ on barberry occurred regularly. Our results indicated that the western China could be the center of origin of $P s t$ and the key hotspot for the pathogen variation. High variation frequencies were revealed by phenotypic and genotypic analyses for sexual progeny of $P s t$, suggesting that sexual reproduction is a major approach for emergence of new races by sexual recombination.

Influence of root exudates and soil on attachment of Pasteuria penetrans to root-knot nematode Meloidogyne arenaria C. LIU (1), P. Timper (2), P. Ji (1), (1) University of Georgia, Tifton, GA, USA; (2) USDA ARS, Tifton, GA, USA 
Pasteuria penetrans is a parasite of root-knot nematode (Meloidogyne spp.). Spores of P. penetrans attach to the cuticle of second-stage juvenile (J2) and subsequently sterilize infected females. This study looked at different factors that influence spore attachment of $P$. penetrans to $M$. arenaria. Incubating $\mathrm{J} 2$ with root exudates reduced spore attachment compared to incubation with phosphate-buffered saline (PBS), suggesting that root exudates altered or blocked spore recognition domains on the nematode surface. Spore attachment was equally reduced following exposure to root exudates from both host and non-host of M. arenaria, indicating there is common signal that affects spore attachment. Root exudates reduced spore attachment more in sterilized soil than in natural soil. Sterilization may have eliminated microbes that consume root exudates. The effect of root exudates on spore attachment was greater in sand than in clay. Clay is likely to adsorb more components from root exudates which may affect spore attachment. Results in this study provide valuable information on the interaction between $P$. penetrans and its host nematode in the root zone of plants and may help improve biological control.

Role of plant innate immunity in the legume, nitrogen fixing symbiosis G. STACEY, University of Missouri, Columbia, MO, USA

The classical model for the evolution of symbiotic systems is that they begin as acute, pathogenic interactions and then evolve through attenuation of virulence, ultimately reaching the state of a commensal or mutualistic interaction. If this model has relevance to the nitrogen-fixing legume symbiosis, it is somewhat surprising that relatively little attention has been paid to the role of plant pathogen defense mechanisms in legume-rhizobium symbioses. There is some research on this topic but this work has been viewed as revealing only ancillary functions and not those central to, for example, the intensely studied Nod factor-signaling pathway crucial to nodulation. However, recent published results appear to signal a shift in the thinking about the role of innate immunity in the nodulation process. For example, it is now clear that type-three, protein secretion systems, classically involved in the delivery of pathogen effector proteins, can play essential roles in nodulation. Likewise, there is now evidence that the rhizobial symbiont can actively suppress host immunity and this, if not essential, does clearly promote nodulation. Thus, my reading of the community is that there is a new appreciation for the potential impact of plant immunity on symbiotic nitrogen fixation. Our laboratory is focusing on elucidating the mechanistic steps by which the plant innate immunity system impacts legume nodulation, including how Nod-factor signaling impacts plant innate immunity. Our results suggest a key role for well-known components of the plant immunity system in core plant functions involved in nodulation.

Exploring fungal DNA virus to control stem rot of oilseed rape caused by Sclerotinia sclerotiorum

H. Zhang (1), Z. Qu (1), S. Liu (1), J. Xie (1), J. Cheng (1), B. Li (2), T. Chen (2), Y. Fu (2), G. Li (1), D. JIANG (1), (1) State Key Laboratory of Agricultural Microbiology, Huazhong Agricultural University, Wuhan, CHINA; (2) College of Plant Science and Technology, Huazhong Agricultural University, Wuhan, CHINA

Sclerotinia sclerotiorum is a notorious fungal plant pathogen with a wide host range. It secretes oxalic acid and plant cell wall-degrading enzymes to kill host cells and tissues. Recent researches revealed that S. sclerotiorum secretes small proteins as virulence factors at the very early stage of infection; these comprehensive mechanisms of pathogenicity likely result in the powerful destructivity of this pathogen and the lack of resistant cultivars. We try to explore hypovirulence-associated mycoviruses to control stem rot of oilseed rape caused by S. sclerotiorum. Previously, we isolated a fungal DNA virus, SsHADV-1, from hypovirulent strain DT-8, and found this virus is highly infectious because its particles could directly infect the hyphae of $S$. sclerotiorum, and could spread horizontally among vegetative incompatible individuals; furthermore, we found that SsHADV-1 could mutualistically interact with a mycophagous insect, Lycoriella ingenua, and use it as a transmission vector. These properties suggest SsHADV-1 has a great potential to control stem rot of oilseed rape. Here, we investigate the survival of SsHADV-1-infected S. sclerotiorum strain on oilseed rape plants after the hyphal fragments were sprayed in field, as well as the efficacy of controlling stem rot. The results suggest that SsHADV-1-infected strain could survive on plants well and control stem rot efficiently.

The need for accurate repeatable diagnostic assays and the pitfalls of testing anomalies: Case study examples from the seed industry S. A. HEUCHELIN, DuPont Pioneer, Johnston, IA, USA

Diagnostic assays are only as good as the rigor of the validation process. Too often the validation process prior to publication is limited and doesn't always show the true limitations of the assay. These issues are often identified when the assay is used in different environs or geographies and false positives or false negatives are observed. These errors in diagnosis for phytosanitary certification can cause commercial or research seed to be rejected entry into a country where it is needed for research and development or to meet market needs. National Plant Protection Organizations (NPPOs) often employ diagnostic assays that they find published in science journals. When these assays are published without extensive inclusivity and exclusivity validation testing, problems often arise from related species or subspecies that exist in the given nation's environs. Both false positives and false negatives can have major repercussions when the test is used for phytosanitary purposes. These direct losses of seed from impoundment, or the inability to get the seed to its destination due to assay error, can cost companies large sums of money or market competitiveness. Many of these issues could be avoided by better assay development and validation and international standardization of diagnostic assays for pathogen species or subspecies. This presentation will illustrate some of these issues and their resolution via real-world examples from the seed industry.

International validation and harmonization efforts for seed health testing G. P. Munkvold, C. C. BLOCK, T. Bruns, Iowa State University, Ames, IA, USA

The global movement of seeds is an essential component of the successful development and marketing of improved crop varieties. Ever-increasing international movement of seeds has called attention to the potential risk of pathogen introduction, resulting in a proliferation of phytosanitary regulations and the development of numerous new seed health testing methods. Methods are often put into use without adequate validation studies, and asynchronous advances in technology across the globe can lead to the use of multiple testing methods for the same host-pathogen combination. This may lead to conflicting results and costly interruptions of research, development, or trade. Lack of communication among National Plant Protection Organizations exacerbates these problems, but a variety of organizations are working toward international harmonization of seed health testing methods. This is a desirable yet challenging goal that requires reliable seed health testing methods supported by robust validation data. National and regional plant protection organizations, the IPPC, and international groups such as the ISHI-Veg program under ISF and the Seed Health Committee of ISTA, have all developed criteria and procedures for validation of seed health testing methods. Cooperation among these groups is intended to facilitate the harmonization of validation criteria, as well as the common use of validated methods for phytosanitary certification.

Obtaining DNA template of adequate purity for amplification and avoiding compounds present that inhibit amplification: A Verticillium dahliae example

G. J. BILODEAU, Canadian Food Inspection Agency, Ottawa, ON, CANADA 
Obtaining a good quality and yield from a DNA extraction is the key in direct detection samples for looking at plant pathogens and organism. In best practices in diagnostic test development, the quality of the DNA is the first step to optimize in order to have success. Over the years, in different projects, we evaluated different DNA extraction methods with optimization in order to obtain the best DNA for Real-Time PCR detection and some metagenomics experiments. Real-time PCR was employed as a tool to determine the best extraction method. Internal controls and specific qPCR assays for Verticillium dahliae and other target organisms were used to determine PCR inhibition (quality) and DNA yield. Soil and water samples were collected and spiked with the target organisms to evaluate the best DNA extraction procedure. From the DNA extraction methods tested, some additional steps with magnetic bead purification and chemical flocculation to remove PCR inhibitors were evaluated. Clearly, the methods giving the highest DNA concentration do not always provide the best quality of DNA, and the ones with the best quality do not provide the highest yield. Removal of PCR inhibitors such as humic acids usually requires addition of a chemical flocculant during the extraction, or a post-extraction step such as magnetic beadbased purification. Further using qPCR to directly targeting organisms, some comparison of kits and methods have also been done for metagenomic analysis using Next generation sequencing (NGS).

Transferring PCR assays into isothermal platforms: How to make sure it works in real world settings T. MILES, California State University-Monterey Bay, Seaside, CA, USA

PCR technologies have been the backbone of molecular diagnostics in plant pathology for almost 30 years. Utilizing these tools researchers have been able to detect various species and genotypes in a variety of environmental samples (e.g. soil, air, and plant tissue). While PCR is powerful it is not without limitations including; 1) the requirement of very clean template DNA, 2) the amount of time required to extract this DNA from environmental samples, and 3) a requirement of a high level of skill to run the assays. Isothermal assays offer significant advantages over traditional PCR assays. Many approaches exist but the two main techniques include loop mediated isothermal amplification (LAMP) and recombinase polymerase amplification (RPA). Like any molecular technology there are advantages and disadvantages to either technique but both approaches are tolerant of PCR inhibitors, can be completed within 30 minutes and can utilize more crude template DNA. Another plus is these assays require significantly less training to perform and have been successfully deployed in field settings to many different groups of plant pathogens. We will discuss examples used in transferring a mitochondrial based PCR marker system for Phytophthora species to LAMP and RPA as well as other examples and compare these approaches in terms of sensitivity, specificity and overall accuracy of the platforms.

\section{USDA APHIS NPPLAP Proficiency Testing and planned methods deviation as a part of the methods' validation process for a network of laboratories V. A. MAVRODIEVA (1), G. Dennis (2), P. J. Shiel (3), (1) USDA-APHIS-PPQ-S\&T-CPHST, Beltsville, MD, USA; (2) USDA-APHIS-PPQ-S\&T- CPHST, Raleigh, NC, USA; (3) USDA APHIS PPQ CPHST, Raleigh, NC, USA}

The National Plant Protection Laboratory Accreditation Program (NPPLAP) mission is to expand USDA Plant Protection and Quarantine laboratory capacity and promote continuous process improvement for diagnostics of regulated plant pathogens by accrediting network laboratories, use of validated diagnostic protocols and Proficiency Testing (PT). A type of inter-laboratory comparison, PT is where a blind randomized set of samples that mimic field samples is sent to network laboratories for analysis using approved methods. Therefore, in addition to testing labs' competency, the PT provides data on methods' performance by different diagnosticians from different laboratory settings and using different equipment. The NPPLAP PT programs for Phytophthora ramorum, citrus greening and plum pox virus have collected multiyear data on the PPQ approved diagnostic methods from approx. 30 laboratories. Analysis of the PT results has provided invaluable data on critical test parameters such as detection limit, precision and range, and methods' fitness for intended use. This and participant feedback have allowed NPPLAP to identify needs for improvement of these methods. The PT data supports the NPPLAP planned methods deviation process. This process is applied to demonstrate comparability of modified methods, used by a particular laboratory, with approved PPQ methods. This allows network laboratories to implement updated technology and higher throughput to fit their needs.

Metagenomic approaches to examine relationships of soil microbial communities with Armillaria root disease

J. STEWART (1), B. Lalande (1), Z. Abdo (1), J. Hanna (2), D. Page-Dumroese (2), M. Warwell (2), J. Tirocke (2), M. S. Kim (3), N. B. Klopfenstein (2), (1) Colorado State University, Fort Collins, CO, USA; (2) Rocky Mountain Research Station, USDA Forest Service, Moscow, ID, USA; (3) Kookmin University, Seoul, Korea, Republic of (South)

Forests harbor highly complex microbial communities that play diverse ecological roles, potentially including protection from root diseases. Armillaria root diseases are highly damaging on diverse woody hosts, and novel approaches are needed for disease management. Soil metagenomic/transcriptomic methods and soil characterization allow a better understanding of complex interactions among soil microbial communities, soil properties, and Armillaria spp. that influence Armillaria root disease in forest ecosystems. Soil cores, Armillaria samples, and tree health data were collected in a western white pine (Pinus monticola) plantation at the Priest River Experimental Forest in northern Idaho. DNA and RNA were extracted from each soil sample, and the ITS-2 and 16S rDNA regions were sequenced through metagenomic techniques to determine the fungal and bacterial communities. Microbial communities and soil properties at each tree were associated with tree health/size and Armillaria species, identified with DNA sequencing of the translation elongation elongation factor- $1 \alpha$ locus. Ongoing analyses are determining if microbial populations differ in relation to Armillaria species associated with diseased/healthy trees and with varying soils properties. Results for this study will be applied to develop novel management approaches for suppressing Armillaria root disease by favoring beneficial microbial communities with potential biocontrol activity against Armillaria pathogens.

Movement of bacteria between plant species drive assembly of epiphytic bacterial communities S. LINDOW, University of California Berkeley, Berkeley, CA, USA

Aerial plant surfaces often support large population sizes $\left(>10^{6} \mathrm{cells} / \mathrm{cm}^{2}\right)$ of a variety of bacterial colonists. The large majority of these colonists occur in relatively large cellular assemblages, apparently driven by localized abundance of limiting carbon resources and more conducive environmental conditions at such sites. Bacterial growth and survival is strongly favored in cellular aggregates, which also are sites of preferential recruitment of immigrant inoculum. Emigration of bacteria from plants is quite efficient and thus the abundance and composition of microbes in air near plants is strongly influenced by the amount and type of vegetation nearby. While some host plant species selection for particular epiphytic bacterial colonists occurs, phyllosphere microbial communities appear to be assembled from a metacommunity contributed and shared by nearby plants in a process that likely involves microhabitat modification at sites of microbial aggregation by initial plant colonists. The selection appears to occur from bacterial strains adapted for life on foliar plant surfaces rather than from other habitats. Leaf surface microbial communities therefore are quite context-dependent and can be managed either by direct inoculation or by changing the agroecological context in which crops are grown. 
Microbial communities of bristlecone needles and resistance in white pine blister rust

A. ALBERTSON (1), Z. Abdo (1), A. W. Schoettle (2), J. Stewart (1), K. Kassenbrock (1), (1) Colorado State University, Fort Collins, CO, USA; (2) USDA Forest Service, Fort Collins, CO, USA

Cronartium ribicola, the causal agent of white pine blister rust (WPBR), threatens susceptible North American pine species, including Rocky Mountain bristlecone pine (Pinus aristata). Since fungal endophytes have been identified to alter a hosts' response to pathogens this research examined the endophytic fungal communities of healthy Rocky Mountain bristlecone pine trees previously inferred to vary in susceptibility to WPBR (using artificial inoculation progeny testing). Three sites were visited in Colorado, where six trees were sampled at each site. Two techniques were used to assay the fungal endophyte community of each tree: culturing from surface-sterilized needles, and of PCR-amplified ITS1 fungal ribosomal gene. Culturing recovered 255 fungal isolates in 33 morphological groups. The Next Generation data yielded over 42,000 usable sequences that were clustered into 789 operational taxonomic units. There was good overlap between both methods; detecting small variations between the fungal communities of individual trees, resistant and susceptible trees, and sites.

Role of leaf microbiome associated with European ash in mediating resistance to ash dieback M. CLEARY, Swedish University of Agricultural Sciences, Alnarp, SWEDEN

Common ash populations in Europe are currently threatened by the alien invasive pathogen Hymenoscyphus fraxineus that is causing extensive decline and mortality. The large-scale population decline will likely have cascading effects on obligate organisms, including fungal biodiversity associated with ash. In this study, we investigate the temporal variation of foliar fungal communities in ash clones as it relates to differential host tree susceptibility to $H$. fraxineus. We hypothesize that (1) hosts genetics influence the fungal communities of leaves, and (2) that fungal communities reflect a tissue-specific and temporal variation during the growing season, but are largely influenced by parasitic growth characteristics of $H$. fraxineus. Leaf tissues, as well as bark and wood, from ash clones exhibiting low-, intermediate- and high susceptibility, were collected at four time points during the summer 2015 in two seed orchards in southern Sweden. Total genomic DNA was extracted and samples representing different host susceptibility, tissue types and time points were Illumina sequenced. Generally, fungal communities of leaves differ from those of bark and xylem, however, this distinction is more clear during the beginning and the end of the growing season. At the beginning of the season, no community differentiation was evident among susceptibility classes, but later (during and after peak sporulation period of $H$. fraxineus), fungal community composition showed some differentiation between low and highly susceptible ash clones. The results support to our initial hypotheses and showed the need of multiple samplings along the season in studies on linkages between fungal communities and host susceptibility patterns.

The Populus microbiome: Progress and limitations of our understanding of phytobiome communities D. JACOBSON (1,2), P. Jones (2), G. Tuskan (1), W. Muchero (1), J. Chen (1), (1) Oak Ridge National Laboratory, Oak Ridge, TN, USA; (2) University of Tennessee, Oak Ridge, TN, USA

The phytobiome (here defined as the combination of the microbiome, mycobiome and viriome) not only interacts with the host, and thus may elicit or suppress a defense response, but there may be interactions amongst the constituents of the phyotbiome. To better understand these influences we have applied modified genome-wide association (GWAS) methods in order to associate host genotypic variation to the putative viral, bacterial, fungal and archaeal community composition. Metatranscriptome samples extracted from Populus trichocarpa xylem and leaf tissue were used to identify the different taxa present via several computational approaches. The resultant members of the phytobiome then served as phenotypes in a GWAS analysis involving 444 genotypes of Populus trichocarpa (against over 28 million single-nucleotide polymorphisms). We view the results as a network and network find shared associations between phytobiome phenotypes and receptor kinases, signal transduction genes, transcription factors, stress and cell organization among other functions. The resultant network provides a rich framework for biologically driven hypothesis generation. Furthermore, we have used the plant gene expression data from these genotypes as expression phenotypes for eQTN analysis. In so doing we are able to identify a significant portion of the regulatory network surrounding the genes that map to the phytobiome phenotypes described above. This unified model is a powerful tool for understanding host-phytobiome associations and the regulatory circuits that control them.

Rapid Ohia Death: The fast track from houseplants to Hawaii's native forests? L. M. KEITH, USDA-ARS, Hilo, HI, USA

Ohia, Metrosideros polymorpha, is Hawaii's most common and widespread native tree, ranging from sea level to $2,500 \mathrm{~m}$ elevation in both dry and wet forests. It is the most ecologically important native tree, defining ecosystem function and providing critical habitat to many endemic and endangered flora and fauna. Rapid Ohia Death (ROD) is a newly discovered phenomenon causing widespread mortality of ohia on Hawaii Island. Crowns of infected, mature ohia trees turn yellow, then brown in a matter of days to weeks. Fungal growth occurs within ohia wood with characteristic staining patterns. Greenhouse and growth chamber inoculation experiments on ohia seedlings and saplings have proven that Ceratocystis fimbriata causes ROD. Several genotypes of C. fimbriata were already present in Hawaii, affecting sweet potato, taro, and Syngonium, a common ornamental plant in the family Araceae. The possibility that $C$. fimbriata from these hosts were the culprit of ROD was examined using pathogenicity tests and phylogenetic analysis and results indicate that no direct link exists. ROD poses a serious threat to Hawaii's flagship native tree species whose loss would be catastrophic for the diversity, structure, and function of Hawaii's remaining native forests and the critical services they provide.

\section{Pathways and populations in Phytophthora: A legacy of destruction}

E. M. GOSS (1), J. Wang (2), (1) Department of Plant Pathology, University of Florida, Gainesville, FL, USA; (2) Kansas State University, Manhattan, KS, USA

The genus Phytophthora contains incredibly successful pathogens in both forest and agricultural ecosystems. Phytophthora species have long taken advantage of cultivated hosts to expand their geographic range. For example, genetic data indicate that early explorers may have spread $P$. palmivora around the world with coconuts. More recently, nursery stock has been implicated in the movement of multiple Phytophthora species, most notably the multiple introductions of $P$. ramorum leading to disease epidemics in wild and cultivated forests. Evolutionary changes in these pathogens are also likely to be responsible for their success upon introduction to new hosts and environments. Several Phytophthora pathogens exhibit high heterozygosity within genomes, which may contribute to their adaptive potential. Some of this intra-individual variation is due to polyploidy. We have found substantial triploidy or aneuploidy even in sexual populations of $P$. infestans. Phytophthora genomes may also exhibit high heterozygosity because they are interspecific hybrids. The tree pathogens $P$. andina, $P$. alni, and $P$. palmivora all exhibit high allelic variation within genomes due to interspecific hybridization. The relative stability of cultivated systems may provide the opportunity for the eventual success of otherwise high risk evolutionary genetic strategies in Phytophthora pathogens. 
Tree domestication and host jump trigger the making of a novel tree disease

N. FEAU (1), R. C. Hamelin (1,2), (1) Department of Forest and Conservation Sciences, University of British Columbia, Vancouver, BC, CANADA; (2) Institut de Biologie Intégrative des Systèmes (IBIS), Université Laval, Québec, QC, CANADA

Tree cultivation is a large contributor to the success in establishment of pathogens, as the use of a few productive clones in intensively managed plantations may encourage susceptibility to diseases. This has been observed in poplars where severe epidemics of native pathogens that were innocuous in their natural pathosystems occurred following host domestication. The North American fungus Sphaerulina musiva is responsible for leaf spots on the eastern cottonwood Populus deltoides. Following introduction of exotic poplar species 100 years ago, a canker disease caused by this pathogen emerged. This disease is severe, causing stem breakage and resulting in plantation failure. By comparing the genome of this fungus to the related poplar leaf pathogen $S$. populicola we found that the acquisition of a gene arsenal required for growth in woody tissues was at the origin of the adaptation of $S$. musiva to colonize trees. Recently, an outbreak of cankers induced by S. musiva was observed on P. balsamifera in Alberta. This suggests a host shift since this is not a known host. Analysis of individuals from this outbreak revealed an unusual pattern of diversity, with islands of diversity separated by fixed genome regions. This new population was likely the result of the hybridization of two individuals followed by limited number of recombination events. The population infecting $P$. balsamifera has strong clonality: we observed a transposon proliferation as well as fixation of the Mat 1.1 allele. The shift from a sexual to a clonal population may constitute one rapid way to fix beneficial mutations. The development and expansion of poplar cultivation triggered changes in a native pathogen, resulting in a specialized population with higher fitness.

\section{Fly without wings: Genetic structure and adaptation of fungal pathogen and associates with bark beetle outbreak in the western Canada and USA}

C. K. M. TSUI (1,2), D. Alayon (1), N. Feau (1), Y. Zhang (1), A. Capron (1), B. Dhillon (3), R. C. Hamelin (1), (1) Department of Forest and Conservation Sciences, University of British Columbia, Vancouver, BC, CANADA; (2) Faculty of Medicine, University of British Columbia, Vancouver, BC, CANADA; (3) University of Arkansas, Fayetteville, AR, USA

Over 18 million hectares of forests have been destroyed in the past two decades in Canada by the mountain pine beetle (MPB) and its fungal symbionts Grosmannia clavigera $(G c)$, Leptographium longiclavatum $(L l)$ and Ophiostoma montium (Om) (Ophiostomatales, Ascomycota). These fungal symbionts are crucial in the establishment and reproductive success of MPB by aiding in nutritional acquisition and overcoming host-tree defenses. Understanding their population structure and adaptations are important to predict their expansion pattern and to improving modeling of beetle epidemics. We investigated their genetic structures using single nucleotide polymorphisms (SNPs) and we monitored fungal growth rates at different temperatures. We found a strong north-south differentiation in their population structure that is strongly correlated with geographical distance. Genetic variation within each species are best explained by distinct spatial and environmental variables. SNP genotyping coupled with genotype-environment association analysis and phenotypic characterization of growth rate, suggested that the coexistence of three MPB fungal symbionts is the result of niche partitioning. We observed that both common (temperature seasonality and host species) and distinct (drought/cold stress, precipitation) environmental and spatial factors shaped these fungal genomes resulting in contrasting outcomes. Intraspecific phenotypic variations in $G c$ and $L l$ suggests potential for adaptive selection in these two species. By contrast, Om displayed narrower intraspecific variation but greater tolerance to high temperatures. Our study highlights the unique genotypic and phenotypic characteristics in these symbionts.

\section{Sphaerulina through history in North America: Consequences of human-aided dissemination} M. L. SAKALIDIS, Michigan State University, East Lansing, MI, USA

Commercial planting practices and strategic breeding for traits that are desirable for commercial production (fast growth, high fiber content) may inadvertently shape the evolution of pathogens that exist on these trees. Domestication of wild pathogens alongside their host can generate new diseases that can have devastating consequences. The Dothideomycete fungus, Sphaerulina musiva is an endemic fungus that occurs naturally on wild poplar in north-eastern and north-central North America where it causes innocuous leaf infections. In domesticated poplars this fungus causes a new disease that results in wounds (cankers) on the stem of the trees- in the most extreme cases trees literally snap in half. In order to manage disease spread, prevent further incursions and identify genes involved in plant attack, a detailed review of historical records and the genomes of 83 strains of the pathogen were decoded. Genes involved in adaptation across all populations and regional adaptation generating local geographic populations were found. These geographic populations also displayed significant difference in virulence profiles on different genotypes of Poplar trichocarpa. Modeling using genomic profiles shows that the pathogen originated in the US, a center of diversity and has repeatedly spread or been introduced into Canada. The most likely vector enabling these repeated introductions is symptomless poplar material exchanged for commercial plantations or breeding programs.

\section{Next-generation sequencing to develop molecular diagnostics for Pseudoperonospora cubensis} L. M. QUESADA, North Carolina State University, Raleigh, NC, USA

Globalization has allowed for rapid movement of plant pathogens that threaten food security. Successful disease management largely depends in timely and accurate detection of plant pathogens causing epidemics. Thus, biosurveillance of epidemic plant pathogens such as Pseudoperonospora cubensis, the causal agent of cucurbit downy mildew, is becoming a priority to prevent disease outbreaks and deploy successful control efforts. Next Generation Sequencing (NGS) facilitates rapid development of genomics resources needed to generate molecular diagnostics assays for $P$. cubensis. Having information regarding the presence or absence of the pathogen, amount of inoculum, crop risk, time to initiate fungicide applications, and effective fungicides to use would significantly contribute in reducing losses to cucurbit downy mildew. We will discuss approaches to identify unique loci for rapid molecular diagnostics using genomic data, to develop molecular diagnostic tools that discriminate economically important pathogen alleles (i.e. mating type and fungicide resistance), and how to use molecular diagnostics with current and future spore trap strategies for biosurveillance purposes of important downy mildew pathogens. The combined use of these technologies within the already existent disease management framework has the potential to improve disease control.

Understanding and managing emerging diseases in the southeastern U.S. using comparative genomics for marker development for fungal plant pathogens

M. T. BREWER, L. G. Sumabat, H. Li, University of Georgia, Athens, GA, USA

Emerging diseases caused by fungi continue to threaten crops in the U.S. and around the world. Understanding if emergence is due to changes in the host, the environment, or the pathogen inform management strategies. Knowledge of the diversity and population genetic structure of pathogen populations is critical for screening for cultivar resistance, and determining appropriate fungicides and rotation crops. Molecular markers are needed to measure genetic diversity, population genetic structure, recombination, and in some cases to infer phenotypes, such as virulence or fungicide resistance. Recently, we have developed molecular markers for several fungi causing emerging plant diseases in the southeastern U.S. using genomics based 
approaches. Markers for genes underlying fungicide resistance, mating-type genes, and microsatellite markers for population structure and genetic diversity have been developed for fungi, including Corynespora cassiicola, a mostly tropical pathogen affecting over 300 plant species that is emerging on cotton, soybean, and tomato in the southeastern U.S., and for Stagonosporopsis species causing gummy stem blight of cucurbits, an economically important disease in the southeastern U.S. and around the world caused by pathogens that rapidly evolve resistance to fungicides. Marker development using genomics approaches and the questions they can answer about pathogen biology allowing us to make informed management decisions will be discussed.

Searching for the genetic basis of phenotypic traits of interest of the causal agent of late blight disease through a genome-wide association study G. DANIES (1), L. Gonzalez-Garcia (1), K. L. Myers (2), H. S. Judelson (3), W. E. Fry (2), S. Restrepo (1), (1) Universidad de los Andes, Bogota, COLOMBIA; (2) Cornell University, Ithaca, NY, USA; (3) University of California, Riverside, CA, USA

Management of Phytophthora infestans, the causal agent of late blight of potatoes and tomatoes has proven to be challenging. This is mainly due to the lack of durable resistance genes and the capability of the pathogen of evolving resistance to certain highly effective fungicides. An understanding of the genetic basis of fungicide resistance would be of value in managing late blight because rapid analysis using molecular markers could inform the selection of the most effective mitigation tactic. In this study, we conducted a genome-wide association study to identify genetic markers associated with sensitivity to mefenoxam in a diverse panel of $P$. infestans isolates. To reduce the number of contigs in the $P$. infestans genome, we reassembled it using Pacific Biosciences sequencing data. The closest genes within a $1000 \mathrm{~kb}$ flanking region, upstream and downstream, of each significant SNP marker associated with sensitivity to mefenoxam in P. infestans were carefully annotated. Further analyses are needed to confirm these associations.

Marker development for Puccinia striiformis f. sp. tritici

X. HU, Northwest A\&F University, China, Yangling, CHINA

Strip rust, caused by Puccinia striiformis Westend. f. sp. tritici Eriks. (Pst), results in severe economic losses for wheat growers in many countries. The current $P s t$ race identification mainly depends on the virulence phenotype of the pathogen on a set of wheat differential genotypes. Usually, the approach needs increasing enough urediniospores and testing a set of differential genotypes in a conditioned greenhouse. Such testing can be limited by space and temperature conditions, and is also time-consuming and labor-intensive. Usually, one person can only identify ca. 400 Pst samples per year. In 1990 s, the moderately repetitive sequences from Pst were developed to identify 96 genotypes among 160 isolates in the Chinese Pst population. In 2000s, RAPDSCAR markers of CYR17, CYR29, CRY31, CYR32, CYR33 and V26 were developed to identify races from large scale field samples. In 2009, we identified 20 new polymorphic microsatellite loci derived from the expressed sequence tag (EST) data of Pst. Since 2015, we developed 5741 SNPs using 15 RNA-seq data set of Pst race CYR32 compared to PST78, among which 67 SNPs associated with 13 SP-SNP (secreted protein SNP) were identified. Now, we are developing SNPs related to virulence variation of Pst based on 600 whole-genome re-sequence data set. In summary, these RAPD-SCARs, EST-derived SSRs, and SNPs will be particularly valuable for virulence-related gene discovery as well as for studies on population evolution, population diversity, and dispersal route of Pst.

Comparative genomics informed detection of Pseudomonas syringae associated with bacterial leaf spot of watermelon and squash E. NEWBERRY (1), D. Mol (2), J. B. Jones (3), M. Paret (4), R. Willmann (2), B. P. Woudt (2), (1) University of Florida, Quincy, FL, USA; (2) Syngenta Seeds, Enkhuizen, NETHERLANDS; (3) Department of Plant Pathology, University of Florida, Gainesville, FL, USA; (4) North Florida Research and Education Center, University of Florida, Quincy, FL, USA

Seed infestation is an important factor contributing to the dissemination of Pseudomonas syringae in vegetable crops. In recent years, disease reports identifying the bacterial species as a leaf spot pathogen of watermelon and squash have increased in frequency in the United States and Europe, indicating a need for improved diagnostic methods. Previous studies have shown the strains associated with disease outbreaks to be members of $P$. syringae phylogroup 2, however genotypic heterogeneity coupled with an unresolved taxonomy pose a serious problem for the precise identification of pathogenic strains. We used comparative genomic approaches to design several molecular markers and screened them against an international collection of over 300 P. syringae strains isolated from contaminated seeds and diseased fields over various years. A phylogenetic analysis of sylC involved in the biosynthesis of the virulence factor syringolin A revealed two divergent groups $\left(s y l C_{a}\right.$ and $\left.s y l C_{b}\right)$ within $P$. syringae phylogroup 2, and a TaqMan probe showed $93 \%$ of the collected strains to possess $s y l C_{b}$. Preliminary pathogenicity testing indicated that the $s y l C_{a}$ strains were weakly virulent to nonpathogenic on squash (cv. Spineless Beauty) whereas all $s y l C_{b}$ strains tested were moderately to highly virulent. In-silico analysis suggests $s y l C_{b}$ to be semi-specific for $P$. syringae strains isolated as pathogens of watermelon and squash, and therefore increased specificity can be achieved with additional strain specific markers.

Light as a driver of phyllosphere microbial behavior G. A. BEATTIE, Iowa State University, Ames, IA, USA

Light is a cue that influences the behavior of foliar bacterial pathogens. Whereas plants exploit light signals to enhance defense against pathogens, we have shown that Pseudomonas syringae exploits light signals to influence movement and colonization, and this may enable it to evade circadian-based plant defenses. Far-red light is enriched relative to blue and red light in plant tissues due to blue/red absorption, enabling far-red light to be abundant within tissues and conducted over long distances through stems and roots. We discovered a much stronger response of $P$. syringae to far-red than to red or blue light, and a significant role of a bacteriophytochrome, a far-red light-sensing photosensory protein, in global gene expression patterns. We have also found that $P$. syringae integrates responses to far-red light, blue light and and water limitation, which are environmental signals that co-occur on leaves. The impact of far-red light and a bacteriophytochrome on $>25 \%$ of the genes in the $P$. syringae genome illustrates a major role for light-sensing in P. syringae biology, consistent with the possibility that this pathogen and others exploit far-red light gradients as spatial and temporal cues within plant tissues.

Nonpathogens in the phyllosphere

J. H. J. LEVEAU, University of California-Davis, Davis, CA, USA

In a 1965 Annual Review of Phytopathology, Curt Leben (1917-2008) argued that the plant disease triangle, i.e. the three-way interaction between a pathogen, its host, and the environment they share, felt overly 'flat' and would benefit from inclusion of a 'fourth dimension' of nonpathogenic microorganisms to better understand plant pathogens and the diseases they cause. Leben ended his treatise with the words: 'How extensive and how important [this fourth dimension] is to the phytopathologist cannot yet be discerned'. In this presentation, I will revisit Leben's idea to see if and how the most recent advancements in profiling this 'fourth dimension' have gotten us any closer to a satisfactory answer regarding the extent and importance of 
nonpathogens in relation to plant disease. I will focus exclusively on aerial plant parts, more specifically the phyllosphere, or leaf surface as a habitat for microorganisms, and will use examples from my own research to show how the assembly, size, composition, and function of leaf-associated, nonpathogenic microbiota may impact or be impacted by the abundance and activity of cohabiting pathogens and so by extension may be able to influence or foretell the manifestation of disease.

Strangers with benefits, remaking the phyllosphere through disease J. D. BARAK, University of Wisconsin-Madison, Madison, WI, USA

Among the complex microbiome membership of the phyllosphere is the periodic inclusion of human enteric pathogens, such as Salmonella enterica. Despite the reoccurrence of S. enterica in the phyllosphere heralded by the numerous outbreaks of salmonellosis due to consumption of raw produce, little is known about the mechanisms which influence its persistence. S. enterica is non-pathogenic on plants, and populations normally decline in the phyllosphere, indicating that it is less fit on healthy plants. Bacteria frequently form alliances in the phyllosphere, resulting in enhanced fitness success. Plant pathogen infection has been shown to be a critical factor for epiphytic persistence of S. enterica on plants. Virulent Xanthomonas perforans (Xp) suppress pathogen associated molecular patterns-triggered immunity resulting in effector-triggered susceptibility which in turn increases persistence of $S$ enterica on infected leaves. Furthermore, we found that $S$. enterica could replicate on plants infected with X. euvesicatoria or X. gardneri. Thus, phytobacterial infections and the disease caused by these pathogens directly increase the risk that produce will maintain viable enteric human pathogen populations. Since our previous work ruled out any physical interaction between $S$. enterica and Xanthomonas, we hypothesize that physiological change to the phyllosphere during disease development influences $S$. enterica populations. Specific changes in the phyllosphere caused by a discrete set of the xanthomonads lead to $S$. enterica replication and changes in colonization sites of the human pathogen revealing an important mechanism that influences this plant pathogen - human pathogen interaction.

An unusual ménage à trois in the phyllosphere

R. R. BÉLANGER (1), J. Laur (2), C. Labbe (2), G. Bojarajan Ramakrishnan (2), P. D. Spanu (3), (1) Université Laval, Québec, QC, CANADA; (2) Université Laval, Quebec, QC, CANADA; (3) Imperial College of Sci Tech \& Medicine, London, UNITED KINGDOM

The phyllosphere harbors a complex microbial community in which fungi occupy a predominant space. In the course of evolution, all leaf surface fungi have acquired specific properties that enable them to compete and survive in this restricted ecological niche in spite of a scarcity of resources. While we, as scientists, have been trying to ascribe a certain hierarchy among the fungi inhabiting the phylloplane, it is nonetheless important to remember that in a balanced environment, each of these fungi manages successfully to acquire the resources necessary for its establishment and reproduction on the leaf surface. In the case of tritrophic interactions involving a biocontrol agent, a fungal pathogen and a plant, they have historically been analyzed solely from the perspective of the mode of action of the biocontrol agent. However, the tripartite association between Pseudozyma flocculosa, powdery mildews and the host plant has seemingly evolved from the conjugated action of the three protagonists. Recent evidence indicates that P. flocculosa can in fact modulate the virulence of powdery mildew fungi and divert the resources that the pathogen extracts from the plant for its own benefit. This intricate mode of action, described as hyperbiotrophy, causes a rapid collapse of the powdery mildew haustorium, which, in turn, leads to a premature death of the pathogen, and brings an end to the interaction.

Get me out of here: Modeling in-canopy turbulence and pathogen dispersion

W. MAHAFFEE (1), B. Bailey (2), N. Miller (3), L. Ulmer (3), E. Pardyjak (3), R. Stoll (3), (1) USDA, Corvallis, OR, USA; (2) University of California, Davis, Davis, CA, USA; (3) University of Utah, Salt Lake, UT, USA

Understanding and predicting how microbes disseminate through the environment requires a nuanced understanding of the factors that influence microbial dispersion beyond data correlations. To this end, we are developing and evaluating the uncertainty in improved modeling tools to predict and examine spatially explicit three-dimensional (3D) canopy microclimate and turbulence. Advances in computational sciences (e.g., ray tracing algorithms, graphics processing unit computing), and biophysical modeling are used to estimate microclimate heterogeneity and its effect on microbial development, while physics-based models are used to estimate in- and above-canopy turbulence and its impacts on dispersion and deposition. These tools are being integrated into a 3D simulation environment that will be used to test hypotheses or to predict temporally evolving dispersion plumes and the probability of infection risk. Our research is showing that the complex architecture of trellised agricultural systems requires an improved understanding of how canopy heterogeneity and local orography interact with meso and microscale events to influence air turbulence and dispersion at field and regional scales.

\section{Citizen science at high school}

M. YAKUB, University of Minnesota, St. Paul, MN, USA

Science outreach and literacy is important, now more than ever. With the advent of new technologies, and communication spreading so fast, we still need to be conversing with our communities about plant pathology, science, and research. To engage plant pathologist and other scientists at the University of Minnesota in science outreach, we oversee three programs: Market Science, Research in High Schools, and the Minnesota Youth Institute. Market Science is a program engaging graduate students, postdocs, and early career scientists to communicate their science in simple terms at a local farmers market. We host a booth with hands-on science activities to engage market goers in general science topics, discussing basic science with adults over coffee. For setting up research at high schools, we work with high school teachers, engaging students in authentic ongoing scientific research. Lastly, we engage plant pathologists to share their work with students who participate in the Minnesota Youth Institute program that engages students in solving local and global hunger issues. While students may think of growing more food as one potential solution, few think of plant diseases affecting hunger. Combined, these outreach programs support scientists and reach out to the community at large while involving students in research. We think that programs like these help scientists better conduct outreach, be accessible to the communities, and the impact is larger than individual connections.

Fostering aGIRLculture: STEM camp solving the grand challenges of the 21st century

D. HADZIABDIC (1), L. Duncan (1), N. Bumgarner (1), F. Critzer (1), L. Edwards (1), K. Gwinn (2), L. Muller (1), C. Stephens (1), M. Velandia (1), C. Buschermohle (1), J. DeBruyn (1), E. Gall (1), J. Logan (1), A. Ludwig (1), A. L. Wszelaki (1), R. Trout Fryxell (1), H. M. Kelly (3), B. H. Ownley $(1,2)$, K. Lewis (1), D. D’Souza (4), K. Jones (1), S. Jean-Philippe (1), E. Willcox (1), M. Prado (1), (1) University of Tennessee, Knoxville, TN, USA; (2) University of Tennessee, Department of Entomology and Plant Pathology, Knoxville, TN, USA; (3) University of Tennessee, Jackson, TN, USA; (4) University of Tennessee, Food Science Department, Knoxville, TN, USA

To meet the demands of increased world population and expectations of feeding approximately 9.7 billion people by 2050 , there is a critical need for expanding post-secondary education focused on science, technology, mathematics and engineering (STEM) disciplines. Current college participation 
rates for rural Tennessee, U.S., are low compared to national standards and students are unaware of professional career opportunities in STEM areas. Although the majority of students that enroll in colleges are female, they are not pursuing STEM disciplines. Recent findings indicated that having a female professor as a guide and role model from a female student's perspective was linked to increased implicit science identity and decreased implicit gender stereotyping. Hence, a team of 24 female faculty members from the University of Tennessee developed and implemented a 3-day summer camp titled 'Cultivating aGIRLculture'. The project objectives were 1) to recruit high school female students from rural communities and expose them to higher education and careers in STEM disciplines, 2) to cultivate a climate that is free of gender biases and stereotypes in STEM careers, and 3 ) to enhance female faculty collaboration across different disciplines to further improve educational, research, and outreach efforts. Data included pre- and post-surveys to evaluate attitudes, perceptions, and knowledge of camp participants, undergraduate chaperones, and faculty collaborators.

Teach the teachers: The Florida experience

M. L. ELLIOTT, University of Florida, Fort Lauderdale, FL, USA

During summer 2016, seven of the University of Florida-IFAS research and education centers located across the state served as hosts for a Plant Pathology Teachers Workshop, using themes from APS: "Healthy Plants=Healthy World" and "Don't Get Caught With Your Plants Down"). The target audience was middle school and high school teachers and 83 people participated. Hard copies of all materials were provided, but the materials were also available, and continue to be available, on-line at http://bit.ly/28J1T19. Much of the material used was obtained from APS resources. The overall increase in plant pathology knowledge was 50\%, and the overall evaluation for the workshop was 4.5, on a 5-point scale with $1=$ low and $5=$ high. Of particular note was the general view that the concepts would not be easy to incorporate into their current science curriculum, but the teachers enjoyed gaining new knowledge. Hands-on activities were included, and teachers stated these were an important aspect of the workshop, especially if designed so teachers can use them in the classroom. However, the main challenge public school teachers face in Florida is the restriction on using microbes in the classroom. There are even restrictions on flowering plants and foods that could be used for experiments. The workshop was also useful as a tool to engage graduate students in teaching and outreach.

Integrating plant diseases into the K-12 STEM classroom

R. L. HIRSCH, University of Kentucky, Lexington, KY, USA

Despite being ideal systems that allow STEM teachers to integrate critical content areas and address relevant teaching standards, plant diseases are largely absent from K-12 STEM curricula. Two case studies present models of partnership that capitalize on the respective strengths of research scientists and STEM educators by fulfilling content standards, meaningfully involving students in the research process, and increasing the broader impact of competitive grant proposals. The first example explores the population genetics of the tall fescue endophyte Epichloë coenophiala. A research field trial was established on public school property, and was utilized as a living laboratory for high school students to learn the process of plot design and sample collection. Research scientists assisted STEM teachers with developing grade-band appropriate curricula modules and assessments based on the ecological implications of fescue/fungi symbioses. In the second case study, APS scientists and STEM teachers utilized bacterial soft rot as a model disease and drafted a middle school laboratory curriculum module. Utilizing these materials, over 200 students manipulated variables of the disease triangle and explored complex host/pathogen interactions. Both case studies offer tangible examples of successful outreach collaborations that benefited the STEM community, broadened the impact of scientific research, and introduced the next generation of scientists to plant pathology.

\section{Nurturing agricultural migrant workforce}

L. SANTAMARIA, Oregon State University, Aurora, OR, USA

There is a growing demand for appropriate training opportunities for the U.S. agricultural workforce. Immigrants make up the majority of this workforce and about $67 \%$ of them are Spanish-speakers. Traditional, face-to-face training is the most common approach in extension, but work schedules make this method a limited option for consistent, ongoing trainings. We are constantly evaluating the educational needs to help this workforce be more efficient in their daily activities. Steps have been taken in this direction to train workers in different aspects of plant health to prevent plant diseases in Oregon's nursery and Christmas tree production systems. One of our new approaches was to develop a hybrid teaching class (blend of online as well a face-to-face instruction) and to assess the reception of this teaching method by immigrant workers. The delivery method was very well received by the participants and the possibility to reach more workers with this approach is promising. Printed educational material is also an important tool to support trainings for this adult audience. Some bilingual materials (pocket booklets, fact sheets, posters, and web responsive and mobile friendly materials) have been developed to create plant disease awareness. This presentation will provide an overview of the challenges and opportunities of creating an active and inclusive educational program geared towards Spanish speaking migrant workers.

Ecology and epidemiology of grapevine red blotch disease

E. CIENIEWICZ, M. Fuchs, Cornell University, Geneva, NY, USA

Red blotch is a recently recognized viral disease of Vitis spp. The causal agent, grapevine red blotch-associated virus (GRBaV) has a single-stranded, circular DNA genome (3,206 nt), and is the type member of the genus Grablovirus in the family Geminiviridae. GRBaV has been detected in all major grape-growing regions of the United States and Canada, likely as a result of the dissemination of infected propagation and planting material. Local spread has been observed in the western United States, warranting further research into the epidemiology of red blotch. Understanding spread of GRBaV requires a multi-pronged approach, including modeling the spatial and temporal attributes of red blotch epidemics, understanding the role of insect vectors, determining the host range, and understanding the mode of transmission. We described a red blotch disease epidemic over three years in a vineyard in California and conducted a survey of hemipteran insects. The pattern of spread observed in this study strengthens management recommendations to rogue and replace under low disease incidence, and replant vineyards under high disease incidence. This survey also provides the first evidence of vector-mediated spread in vineyards and identifies potential vectors in the vineyard. Understanding epidemiology and transmission will inform proper management strategies to minimize spread of GRBaV.

Optimization of fungicides for disease management and enhanced overwintering of stevia A. KOEHLER, North Carolina State University, Raleigh, NC, USA

There are many challenges facing the establishment of stevia (Stevia rebaudiana) as a perennial crop in the US. Southern blight (caused by Sclerotium rolfsii) and Septoria leaf spot (caused by Septoria sp.) are the most economically important diseases in the southeast. Fungicide efficacy trials for management of these diseases were conducted between 2014 and 2017 and multiple products for management of S. rolfsii and Septoria were identified. 
Crowns from fungicide trials in 2014 were left in the field to overwinter and stand counts were taken in spring 2015 to determine percent emergence compared to final stand counts in fall 2014. Treatments that received one or more applications of the QoI (strobilurin) fungicide azoxystrobin had enhanced overwintering survival (mean survival rate, $78 \%$ ) compared to other fungicides (38\%), and the non-treated control (38\%). In spring 2016, plots receiving QoI treatments in 2015 had higher overwintering emergence compared to controls at two locations. Roots and crowns were destructively sampled in spring 2016 and QoI treated plants had higher mean weights $(62 \mathrm{~g})$ compared to non-treated controls $(31 \mathrm{~g})$. Trials planted in 2016 were destructively sampled monthly for 12 months to record root weights and document fungi associated with roots throughout the growing season and overwintering. This study may open a new avenue of investigation into the role of fungicides and the root phytobiome in the vigor and survival of perennial plants.

Microbiome networks: A systems framework for identifying candidate microbial assemblages for disease management in the era of genomics and phytobiomes

R. POUDEL (1,2,3), L. Meyer (4), A. Jumpponen (5), M. M. Kennelly (6), C. L. Rivard (4), D. C. Schlatter (7), T. C. Paulitz (7), B. B. McSpadden Gardener (8), L. L. Kinkel (9), K. A. Garrett (1,10,11), (1) Plant Pathology Department, University of Florida, Gainesville, FL, USA; (2) Emerging Pathogens Institute, University of Florida, Gainesville, FL, USA; (3) Institute for Sustainable Food Systems, University of Florida, Gainesville, FL, USA; (4) Kansas State Research \& Extension Center, Olathe, KS, USA; (5) Biology Department, Kansas State University, Manhattan, KS, USA; (6) Department of Plant Pathology, Kansas State University, Manhattan, KS, USA; (7) USDA ARS, Pullman, WA, USA; (8) Ohio State University, Wooster, OH, USA; (9) University of Minnesota, St Paul, MN, USA; (10) Emerging Pathogens Institute, Gainesville, FL, USA; (11) Institute for Sustainable Food Systems, Gainesville, FL, USA

Network models of soil and plant microbiomes present new opportunities for enhancing disease management and plant health, but also challenges for interpretation. We present a framework for network analysis and apply it to multiple microbiome datasets, to generate testable hypotheses about candidate taxa affecting plant health. This framework includes four analyses. "General analysis" identifies candidate taxa for maintaining an existing microbial community, and useful for comparison of microbiomes when host or pathogen responses are absent. "Host-focused analysis" includes a node representing a plant response such as yield, identifying taxa with direct or indirect links to that node, which are interpreted as potentially beneficial or detrimental to plant health. "Pathogen-focused analysis" identifies taxa with direct or indirect links to taxon nodes known a priori to represent pathogens, which can be interpreted as agonists or antagonists. "Disease-focused analysis" identifies nodes for both plant-pathogen responses. We illustrate the interpretation of networks with microbiomes in the oak phyllosphere, in soil associated with the presence or absence of infection by Rhizoctonia solani, and in a new example of the tomato rhizosphere influenced by rootstock genotypes and grafting. Such analyses can be used to characterize microbes and conditions involved in the suppression of pathogens, the biofertilization of plants, and/or the expression of host resistance in plants.

Effects of three chemical compounds on Ralstonia solanacearum physiological functions and disease development H. T. TSENG, A. L. Mila, North Carolina State University, Raleigh, NC, USA

The effects of three chemical compounds, known to have anti-microbial activities, were examined against Ralstonia solanacearum (Rs). The compounds were 3-indolyacetonitrile (IAN), p-benzoquinone (pBQ), and 6,7-dihydroxycoumarin (6-7-D). The minimal inhibition concentration against Rs was $640 \mu \mathrm{M}, 25 \mu \mathrm{M}$, and $125 \mu \mathrm{M}$ for IAN, pBQ and 6-7-D, respectively. Sub-inhibitory concentrations, $160 \mu \mathrm{M}$ for IAN, $12.5 \mu \mathrm{M}$ for $\mathrm{pBQ}$, and 50 $\mu \mathrm{M}$ for 6-7$\mathrm{D}$, were used to determine bacterial growth rates. IAN was significantly more effective in inhibiting growth compared to pBQ and 6-7-D. Fluorescent microscopy with GFP-labeled W7 strain demonstrated that IAN limited bacterial colonization of plant roots the most. Tobacco cultivars K326 and Speight 168 were treated with the compounds 48 -hours before, at the same time or 48 -hours after inoculation. IAN was the most effective compound in limiting disease and treating at inoculation suppressed the disease the most regardless of the compound. Quantitative real-time PCR revealed that pBQ significantly inhibited the expression of the three pathogenicity-related genes, $p h c A, x p s R$, and pehR, compared to the untreated control whereas 6-7-D did not have any significant effect. With IAN, expression of $p h c A$ and $x p s R$ was repressed, but the expression of pehR was increased. Understanding the unique Rs physiological traits and their responses to stimuli may provide insights for future phytobiome research.

Global efforts to control potato cyst nematodes

L. M. C. DANDURAND, University of Idaho, Moscow, ID, USA

In today's globalized world, intensified international trade has increased the risk of an introduction of noxious pests, including the economically important potato cyst nematodes (PCN). Native to South America, PCN are some of the most specialized nematode pests in agriculture. PCN are limited in host range to potato and a few other solanaceous crops, and are well adapted to survive in soil for many years. The cyst, the remnants of the body wall of the female, contains 200-500 eggs which remain dormant until stimulated to hatch by root exudates from its host. Infestation retards plant growth, and as a result yield can be decreased by up to $80 \%$. In the US, stringent adherence to phytosanitary programs have contained Globodera rostochiensis to eight counties in New York, fewer than 6,000 acres, despite its documented presence since 1941. The infestation of Globodera pallida, first found only in Idaho in 2006, continues to be contained to fewer than 3,000 acres which is less than $1 \%$ of the total acreage planted to potato in Idaho. Trade of potato from the US and from Idaho, originally interrupted by the detection of G. pallida, has resumed with Canada, Mexico and South Korea, whereas negotiations to resume export of potato from Idaho to Japan are ongoing. The use of containment and quarantine methods, plant resistance, soil fumigation, and alternatives to fumigation in the United States, and elsewhere in the world against potato cyst nematodes will be discussed.

\section{Breadth of nematode effectors}

M. G. MITCHUM, University of Missouri, Columbia, MO, USA

The discovery of the first nematode effector protein was nearly twenty years ago. Since then, the identification of a vast array of effector proteins has revealed the incredibly complex nature of nematode parasitism of plants. The types and putative functions of currently known nematode effectors span from cell wall degrading enzymes acquired by horizontal gene transfer to sophisticated peptide mimics that may have arisen through convergent evolution. Some effectors are common among nematode species, whereas other classes of effectors seem to be a defining feature of a particular group of nematodes. Although some effectors harbor features common among effectors of other types of pathogens, the majority of nematode effectors are unique to these eukaryotic pathogens. Recent advances in effector function have identified a list of host targets to unveil the diversity of cellular processes modulated by these parasites. However, the recent release of phytonematode genomes coupled with the application of novel effector prediction tools suggest discovery efforts are not saturated. As for function, we have only scratched the surface and only recently, researchers have recognized secreted small molecule effectors as key factors in plant-nematode interactions. As we look to the future, nematode effector libraries represent amazing resources of untapped potential for engineering plant resistance to one of agriculture's most devastating groups of pathogens. 
Nematode parasitism genes and their manipulation of host plants

C. GLEASON (1), L. Zhang (1), N. Leelarasamee (2), J. Utermark (2), S. Habash (3), A. Elashry (3), (1) Washington State University, Pullman, WA, USA; (2) Georg August University, Goettingen, GERMANY; (3) Bonn University, Bonn, GERMANY

In the Pacific Northwest, root-knot nematodes (Meloidogyne spp.) are a serious problem on potatoes. There is a critical need to reduce the use of toxic chemicals in nematode management. In order to develop the tools for engineering nematode resistance in potato, we must first understand the molecular components of plant defense and the nematode strategies used to overcome these defenses. During infection, the nematode secretes molecules called effectors. The effectors suppress plant defenses and/or alter the host physiology to enable successful nematode infections. Our lab studies root-knot nematode effectors, and we identified a novel effector called Mh265. Plants that ectopically express Mh265 were more susceptible to nematode infection. Interestingly, Arabidopsis that expressed Mh265 exhibited a suppression of elicitor-induced callose deposition. We concluded that Mh265 is secreted by the nematode in order to modulate basal plant immunity. In addition to effectors, our group is also interested in plant immune responses during nematode infections, and in particular, we have focused on the role of the defense hormone jasmonic acid (JA). Using several mutants in JA biosynthesis/perception, we were the first to find that a jasmonic acid precursor called OPDA acts as a defense-signaling molecule in the plant-nematode interaction. This result has given us insights into the mechanisms regulating plant defenses against nematodes.

The soybean cyst nematode: Managing a chronic disease using sustainable approaches

K. LAMBERT, University of Illinois, Urbana, IL, USA

The soybean cyst nematode (SCN), Heterodera glycines, is a damaging pest of soybean that has been spreading within the U.S. for over 60 years. The nematode is now found in all soybean producing states and causes significant yield losses each year. SCN owes its persistence to cysts that protect its eggs for many years. The economics of growing soybean do not support the use of soil-applied nematicides, but many natural SCN resistant germplasm accessions have been discovered. A diverse set of SCN resistant soybeans have been developed in academic laboratories, but the majority of commercially available SCN resistant varieties are derived from one source of resistance, PI88788. The over use of one SCN resistance mechanism has applied a strong selection pressure on SCN populations, causing an increase in nematodes that can reproduce on resistant plants, or virulent SCN. In theory, SCN could be managed more effectively if soybean with different mechanisms of resistance could be rotated. However, for rotation strategies to be effective the virulence profiles of nematode populations must be known and plants with the most effective SCN resistance must be grown. For this kind of precision agriculture to be implemented, rapid methods of measuring SCN virulence need to be deployed and new mechanisms of SCN resistance must be bred into commercial soybean varieties. New insights into understanding SCN resistance in soybean, and virulence in the nematode, promise to produce diagnostic technologies that can be used for sustainable SCN management.

\section{Mechanisms of susceptibility to bacterial blight in cotton}

K. Cox (1), L. SHAN (2), (1) Dept. Plant Pathology and Microbiology, Texas A\&M University, College Station, TX, USA; (2) Texas A\&M University, College Station, TX, USA

The interaction between cotton and Xanthomonas citri subsp. malvacearum $(X \mathrm{~cm})$, which causes bacterial blight of cotton (BBC), is one of the first examples to study classical gene-for-gene resistance in plants. BBC is also among the most devastating diseases of cotton worldwide, in particular with recent outbreaks in the United States. The quantitative trait loci and recessive inheritance of certain BBC resistance, the complex genome and tetraploid nature of this important crop, as well as limited molecular and genetic tools, make the isolation of cotton resistance $(R)$ or susceptibility $(S)$ genes extremely challenging via traditional map-based cloning. We have deployed single molecule real-time sequencing of two well-studied $X \mathrm{~cm}$ strains and assembled the whole repertoires of transcription activator-like (TAL) effectors, which are key pathogenicity determinants in xanthomonads. By combining genome-wide expression profiling of cotton cells expressing a specific TAL effector and code-assisted bioinformatics prediction of TAL effector binding element (EBE), we identified GhSWEET10, encoding a sugar transporter, as a key $S$ gene to BBC. The TAL effector from Xcm massively induces GhSWEET10 expression by directly binding to the EBE of its promoter. Remarkably, activation of GhSWEET10 by designer TAL effectors restored $X \mathrm{~cm}$ virulence, and silencing of GhSWEET10 in cotton reduced its susceptibility to Xcm infection. A sucrose FRET sensor assay demonstrated that GhSWEET10 is a functional sugar transporter. The work provides an example of identifying $S$ target in a tetraploid species and suggests that pathogen-induced GhSWEETscontribute to disease progression by transporting sugar into apoplasts.

The advent and spread of prodigious multi-fungicide resistance in Botrytis cinerea

G. SCHNABEL (1), M. Hahn (2), N. Peres (3), M. Hu (1), (1) Clemson University, Clemson, SC, USA; (2) Department of Biology, University of Kaiserslautern, Kaiserslautern, GERMANY; (3) Gulf Coast Research and Education Center; University of Florida, Wimauma, FL, USA

Of all fungal plant pathogens, Botrytis cinerea is perhaps the most capable of developing fungicide resistance. This causal agent causes gray mold disease on dozens of ornamentals, vegetables, and fruits worldwide. Over the last six years we have been monitoring strawberry fields in the eastern Unites States and reported simultaneous chemical class resistance (CCR) to up to 7 different classes of fungicides. Genetic analysis revealed that resistance is mostly qualitative in nature and based on point mutations in target genes. In contrast, resistance to fludioxonil is primarily based on Mrr l transcriptional activator-driven overexpression of the drug efflux pump AtrB. Multiyear resistance screening revealed at first an increase in CCR that was aided at least in part by 'selection by association' where fungicide resistance traits were likely linked to the trait being selected rather than being the selected trait itself. But in recent years the frequency of multi-CCR isolates in strawberry populations has stabilized. This stabilization may be due to recent efforts to implement resistance management on the nursery level, the implementation of location-specific resistance management practices, and the recently described impairment of multi-CCR isolates to compete with sensitive isolates. The newly discovered species Botrytis fragariae is a frequent colonizer of strawberry flowers in Europe and the USA and multifungicide resistance in this pathogen is also ubiquitous. However, the role of B. fragariae in pre- and postharvest fruit rot is still unclear.

\section{Evolution of multi-fungicide resistance in cereal pathogens and impact on disease control}

\section{B. B. FRAAIJE, Rothamsted Research, Hertfordshire, ENGLAND}

NW-Europe is always under high disease pressure of fungal pathogens due to favourable weather conditions and a high intensity of cereal production. Host resistance breeding has provided good control of powdery mildews and rusts, albeit subjected to boom-and-bust cycles of major single resistance genes, but it has proved more difficult to control diseases such as Septoria, net blotch and Ramularia. Control of these diseases has been heavily dependent on chemical control. Unfortunately, pathogens like Zymoseptoria tritici, Pyrenophora teres and Ramularia collo-cygni have been able to shown a remarkable adaptation to fungicides over the years and current UK field populations are resistant or less sensitive to different groups of systemic fungicides, including benzimidazoles, quinone outside inhibitors and azoles. As a consequence, farmers have only a few options available to control these diseases. Further threats for disease control are the first reports of resistance development to the most effective group of fungicides, the succinate 
dehydrogenase inhibitors (SDHIs), in different pathogen field populations, and loss of current actives and drying up of the fungicide pipeline due to tighter legislation. DNA diagnostics able to measure the dynamics of SDHI-resistant alleles in Z. triticipopulations are now being used to establish which strategies are most effective for resistance management and can help to extend the shelf life of current and future fungicides.

\section{Rethinking apple IPM}

J. L. BECKERMAN (1), G. W. Sundin (2), (1) Purdue Univ, West Lafayette, IN, USA; (2) Michigan State University, East Lansing, MI, USA

More than 100 pathogens infect apples, but apple scab, caused by the fungus Venturia inaequalis, has significant economic impact worldwide. In eastern North America, an integrated pest management (IPM) approach has been widely implemented to address a variety of crop constraints. IPM is defined as a "science-based, decision-making process that identifies and reduces risks from pests and pest management related strategies...IPM serves as an umbrella to provide an effective, all encompassing, low-risk approach to protect resources and people from pests." For apples, as for many crops, growers assume all the risk. In their management of risk, fungicides serve as an insurance policy against crop loss, with growers applying 12-25 applications of fungicides per season for commercially acceptable control of apple scab and other diseases. When the cost of production is high and tolerance for disease-related damage is low, populations of scab with resistance to multiple classes of fungicides have increased grower risk and fungicide use. Changes in apple scab management, including increased reliance on captan, may be driving outbreaks of previously once-managed diseases. This unintended consequence of incorporating fungicide resistance management into IPM suggests that IPM is necessary for disease management, but that it may not be sufficient to address all the issues facing fruit growers today.

\section{Healthy vegetables at the cost of multi-fungicide-resistant pathogens} M. T. MCGRATH, Cornell University, Riverhead, NY, USA

A commonly recommended and implemented resistance management strategy is applying in alternation fungicides with different modes of action (different chemical groups based on FRAC code). Premise is that cross resistance occurs among related but not unrelated fungicides, because mode of resistance usually is the result of changes in different target-sites, and also that pathogen strains with resistance to multiple chemistries are unlikely to develop or be fit to survive. Unfortunately, resistance has developed to multiple chemistries in single strains of several pathogens causing key diseases in vegetables, including powdery mildew of cucurbits (FRAC Code 1,7,11, and 13), gummy stem blight of cucurbits (1, 7, and 11), early blight of potato (7 and 11), Fusarium dry rot of potato (1 and 12), and likely downy mildew of cucurbits (4 and 11 plus 28 and/or 43). Stepwise accumulation of resistance to fungicides with successive exposure is the assumed reason. When the first fungicides at risk for resistance development were registered there was not other chemistry to use in alternation except multi-site contact fungicides, which typically are less effective. However, recent cases of resistance (cucurbit powdery mildew pathogen developing resistance to FRAC Code 13 fungicide in addition to Codes 1,7 , and 11) occurred when there were ample chemistries to alternate with $(3, \mathrm{U} 6$, and U8). Premixes can contribute to the problem when resistance has developed to one ingredient.

\section{Multiple fungicide resistances in Cercospora beticola of sugar beet} G. A. SECOR (1), V. Rivera-Varas (1), M. D. Bolton (2), (1) North Dakota State University, Fargo, ND, USA; (2) USDA ARS NCSL, Fargo, ND, USA

Cercospora leaf spot (CLS), caused by the fungus Cercospora beticola, is the most damaging disease of sugar beet worldwide. It is endemic in the midwestern region of the US causing yield losses and reduced sugar quality. Disease is managed by a combination of crop rotation, resistant varieties and timely fungicide applications. This integrated management strategy has minimized disease losses with no major disease outbreaks for many years. Six fungicides from four classes of fungicides are applied one to six times during the growing season. The fungicides used are triphenyl tin hydroxide, thiophanate methyl, tetraconazole, difenoconazole, prothioconazole and pyraclostrobin. Since 1998, sensitivity to these fungicides has been monitored in over 1000 samples/year from commercial fields collected by sugar company agronomists throughout Minnesota and North Dakota. Changes in sensitivity to all fungicide classes have been documented in all factory districts, and isolates with resistance to multiple fungicide have steadily increased since 2013. In 2016, $14.4 \%$ of the isolates tested $(\mathrm{n}=1326)$ were resistant to all fungicide classes used for CLS management. The combination of decreased fungicide sensitivity, resistance to multiple fungicide classes and increased disease pressure in recent years may have an impact on future disease management and an accelerated need for resistant varieties.

\section{How to manage multiple fungicide resistance in plant-pathogenic fungi}

\section{G. STAMMLER, K. Klappach, BASF SE, Limburgerhof, GERMANY}

Examples for multiple resistance can be found in different plant pathogenic species such as Botrytis cinerea, Zymoseptoria tritici, Plasmopara viticola and others. Frequency of resistance is mainly driven by selection pressure on the one hand and fitness penalties on the other. Since targets site mutations concern often highly conserved amino acids (aa), it could be postulated that aa exchanges reduce enzyme efficiency, which has been previously shown e.g. for SDH aa exchanges. Reduced enzyme efficiency could be relevant for the fitness of resistant strains in the field and thus, depending on presence or absence of selection pressure, have an impact on the effectiveness of resistance management strategies. Fitness costs of multiple resistances might accumulate in individual strains and have a negative influence on their competitiveness with wild type strains as indicated in studies with $B$. cinerea, $Z$. tritici and $V$. inaequalis. However, in multiple resistant strains, resistance to a specific mode of action (MoA) can be co-selected by application of other MoAs. This was found in B. cinerea, where AP resistance was selected by KRI applications in presence of double (AP+KRI) resistant strains. This can be a challenge to the effectiveness of conventional resistance management strategies. Therefore, strategies should focus on the reduction on disease and selection pressure, namely on phytosanitary measures, limitation of number of applications and the use of biological agents. Also alternation and mixing of fungicides with appropriate MoAs, including multi sites offer efficient management strategies.

\section{Multiple resistance in fungal plant pathogens, its selection schemes and impact on disease control management strategies} S. TORRIANI, Syngenta Crop Protection, Stein, SWITZERLAND

Several fungicide classes are used to control a fungal disease. Fungicide classes inhibit independent biochemical targets and are often applied in mixtures or in spray program during the season. By sexual recombination or accumulation of independent mutations, multiple resistant individuals can be selected. Each resistance is characterized by different resistance factors, fitness, frequency and impact on field performance. Multiple resistances have been observed in various pathogens including Zymoseptoria tritici, Plasmopara viticola and Botrytis cinerea. Z. tritici evolved resistance to MBC, DMI, QoI and SDHI fungicides, but also might express weak multidrug characteristics. P. viticola developed resistance to PA, QoI, CAA and cymoxanil. B. cinerea showed targeted and multidrug resistance towards a range of fungicide classes. Whereas frequency of single resistance is high, the combined resistance might remain at lower frequencies and can be managed through appropriate spray applications and good agronomic practices. Multiple fungicide resistance can follow different evolutionary directions in response to the selection imposed by the spray strategies (alternation/mixtures), the number of 
registered products, the characteristics of each fungicide and the putative contribution of multidrug resistance. A better understanding of how multiple resistances evolve is beneficial to frame the impact to disease control and to propose sound new anti-resistance strategies.

The phytobiome and biological control: What does the future hold?

J. E. LEACH, Colorado State University, Fort Collins, CO, USA

Meeting demands for food, feed and fiber will require doubling production in less than 35 years, and doing so in the face of increasing resource constraints, extreme weather events, uncertain water availability, and increasingly limited arable land. The Phytobiomes Roadmap, published in 2016, offered a vision for sustainable crop productivity obtained through a systems-level understanding of diverse interacting components. One component of the phytobiome that is being actively targeted for improving healthy crop production is the plant microbiome. Strategies involve the incorporation of beneficial microbiomes into agricultural systems by managing, selecting, or engineering microbiomes that enhance plant growth, nutrient use efficiency, tolerance to abiotic stresses, or disease resistance, including biological control. However, there are many knowledge gaps that need to be closed to successfully and sustainably translate this information to the field; these gaps and strategies to approach them will be discussed in this presentation.

What happens to good results? From the academic research lab to labeled product for growers B. J. JACOBSEN (1), M. B. Dimock (2), (1) Montana State University, Bozeman, MT, USA; (2) Certis USA, LLC, Columbia, MD, USA

This presentation will discuss the pathways and pitfalls in developing a commercial biological control. Focus will be on initial discovery, laboratory research, taxonomic identification, deposit of reference samples with national or international culture collections, development of provisional and final patents, publication, field testing and working with companies who will develop a product and regulatory agencies who will label a product. Precautions and suggestions on sharing samples early in the discovery and development phases, field testing and testing for key commercial markets will be discussed. The 20 year development of Bacillus mycoides isolate $\mathrm{J}$ into the product LifeGard

The new biofungicide natamycin as a preplant dip treatment against QoI-resistant populations of Colletotrichum acutatum in strawberry S. E. HAACK (1), K. L. Ivors (2), G. J. Holmes (2), H. C. Förster (1), J. E. Adaskaveg (1), (1) Department of Plant Pathology and Microbiology, University of California, Riverside, CA, USA; (2) Strawberry Center, California Polytechnic State University, San Luis Obispo, CA, USA

Anthracnose crown rot of strawberry, caused by Colletotrichum acutatum $(\mathrm{Ca})$, is an important disease in California nursery transplant and fruit production. In nursery plant multiplication, the disease can increase in wet years or with overhead irrigation and may reach epidemic levels when infected plants are moved to fields for fruit production. Cyprodinil/fludioxonil and azoxystrobin are currently registered as pre-plant dips of bare-root transplants. Additional management options are needed because of phytotoxicity concerns with cyprodinil/fludioxonil if roots are over-exposed to the treatment and presence of $\mathrm{QoI}$ resistance in $\mathrm{Ca}$ populations. The broad-spectrum biofungicide natamycin, never reported to develop resistance in filamentous fungi, was evaluated for its in vitro toxicity and as a dip treatment. Mean $\mathrm{EC}_{50}$ values for mycelial growth of 45 QoI-sensitive and 29 resistant $\mathrm{Ca}$ isolates were 0.996 and $0.902 \mathrm{mg} /$ liter, respectively. Dipping transplants inoculated with QoI-sensitive or -resistant $\mathrm{Ca}$ for 5 minutes in 500 or $1000 \mathrm{mg} /$ liter natamycin reduced plant mortality in the field by 58 to $95 \%$ as compared to the control $(42 \%$ or $72 \%$ mean mortality for cultivars Fronteras and Monterey, respectively). Fludioxonil/cyprodinil reduced mortality by 86 to $100 \%$. Azoxystrobin was only effective against QoI-sensitive isolates, reducing mortality by 80 to $92 \%$. Based on this work, registration of natamycin as a dip treatment of strawberry transplants is in progress.

Accelerating microbial products for sustainable agriculture

S. HUSE, V. Urisn, Indigo Ag, Charlestown, MA, USA

Achieving the goal of global food security will require increased investment in productivity and agricultural sustainability. Development of microbial products to achieve environmental sustainability and productivity of agriculture is a growing industry. Indigo $\mathrm{Ag}$ (www.indigoag.com) is focused on products using microbial endophytes and has developed a large and sophisticated pipeline to test plant-microbe interactions, from microbial discovery through field trials. Indigo pioneers a unique innovation model that accelerates the time-to-market of new technologies and enables continuous improvements once products are launched as commercial data are collected to inform product development. Through collaboration with us, we can help scientists translate their research into applied agricultural products. By working with growers closely, we can improve our products to better respond to their changing needs and adjust to diverse growing conditions. Indigo released its first product in 2016, Indigo ${ }^{\text {TM }}$ Cotton, that was developed in collaboration with Texas A\&M. Launched on approximately 50,000 acres, Indigo ${ }^{\mathrm{TM}}$ Cotton showed a $11 \%$ increase in targeted fields. The Indigo innovation model enables us to launch products in a 2-3 year timeframe compared to 10-15 years for many agriculture technologies.

Characterization of antimicrobial-producing beneficial bacteria from citrus rhizosphere

N. RIERA (1), Y. Zhang (2), U. Handique (1), N. Wang (1), (1) University of Florida, Lake Alfred, FL, USA; (2) CREC, University of Florida, Lake Alfred, FL, USA

The microbiomes associated with crop plants have a strong impact on plant health and productivity. Here, we present our work on the isolation and characterization of putative beneficial bacteria from healthy citrus rhizosphere and test whether they can be used to control citrus diseases caused by Candidatus Liberibacter asiaticus (Las) and Phytophthora. Six isolates were tested for antibacterial activity against three bacteria closely related to Las: Agrobacterium tumefaciens, Sinorhizobium meliloti and Liberibacter crescens since Las has not been cultured. We also test the antifungal activity. Four isolates with antagonistic activity against the citrus root pathogen Phythopthora nicitianae were identified to belong to Stenotrophomonas, Bacilli and Burkholderiaceae families. We sequenced the genomes of Pseudomonas geniculata strain 95 and Bacillus pumilus strain 104 to explore genes associated with beneficial traits. We will discuss how the identified antimicrobial-producing bacteria contribute to disease control.

Nonbiological biological control

G. HARMAN (1,2), A. Moreno (3), W. Nosir (3), M. Cadle-Davidson (4), (1) Advanced biological marketing, Geneva, NY, USA; (2) Cornell University, Geneva, NY, USA; (3) Advanced Biological Marketing, Geneva, NY, USA; (4) Advanced Biological Marketing, Inc, Geneva, NY, USA

Biocontrol and plant growth promotive microbes, especially endophytic ones, interact strongly with plants. They frequently do so via chemical communication with plants. These chemical communicants are, by necessity, active at very low concentrations and may provide many of the same benefits as the microbial agents that produce them. One advantage of use of these biorational compounds is that it may be possible to use these in environments, e.g., in the presence of chemical pesticides and surfactants, that would be lethal to the microbial agents that produce them. An example of such microbial metabolites are the lipopolysaccharides from Bacillus spp. In our studies with Trichoderma strains, we evaluated 1-octen-3-ol (1o3) and 
6-penyl pyrone (6PP). In field trials, seed treatments with $1 \mathrm{ul} / \mathrm{seed}$ or less of 103 induced many of the same effects in corn as did the strains from which they were produced. Plant growth and yields were enhanced and root growth was remarkably stimulated. Similarly, resistance to abiotic stresses such as flooding also was enhanced. In greenhouse tests, both 103 and 6PP had similar effects on both corn and soybeans. The effects in the field lasted for the life of at least an annual crop. Clearly, the chemicals must induce changes in the plant, perhaps through epigenetic changes in the nucleic acid and/or through long-term alterations in the plant microbiome. Formulation and delivery systems with these chemicals are being developed.

\section{Management of downy mildew of lima bean: Chemical control}

T. MHORA, A. Duckett, N. F. Gregory, T. A. Evans, N. M. Donofrio, University of Delaware, Newark, DE, USA

Lima bean, the cornerstone crop of Delaware, is adversely affected by downy mildew caused by the oomycete pathogen Phytophthora phaseoli. When uncontrolled, downy mildew results in devastating yield loss in the mid-Atlantic region (MAR). Chemical control and host resistance are important tools for the MAR and are being improved upon to increase lima bean profitability. Genetic resources have been developed for cultivar development, including the phenotypic characterization of a 256-member diversity panel for traits which include resistance to race $\mathrm{F}$ of $P$. phaseoli. Chemical control is however the major management strategy, with mefanoxam (Ridomil Gold) being the most widely applied fungicide. Reports of resistance have initiated assessment of the mefanoxam tolerance of MAR isolates collected over the past four seasons. Isolates were tested for mefanoxam sensitivity by assessing their growth on frozen lima bean media containing mefanoxam concentrations of $0 \mathrm{ppm}, 50 \mathrm{ppm}$ and $100 \mathrm{ppm}$. Single sporangial isolate subsamples of field populations were compared to their corresponding field isolate, with five of 101 isolate sets showing mefanoxam insensitivity. Morphometric differences observed between these insensitive isolates and their composite counterparts suggested mixed populations in the field, a possible explanation for genotype data that shows a lack of diversity between isolates. This data will allow farmers to be informed on better fungicide usage practices.

Plant-parasitic nematodes associated with potatoes (Solanum tuberosum L.) in different soil texture classes from Costa Rica R. SANDOVAL RUIZ, L. Flores Chaves, D. Humphreys Pereira, University of Costa Rica, San José, COSTA RICA

Potatoes are one of the most consumed crops in the world and it is essential for food security in many countries. Among the phytosanitary problems associated with potatoes worldwide are nematodes, mainly Globodera, Meloidogyne and Pratylenchus. Information about the frequency and distribution of nematode species in potatoes is lacking in Costa Rica. This knowledge is essential to implement effective management strategies against nematodes. The objectives of this research were to identify the plant-parasitic nematodes associated with potatoes from the two main potato-growing regions of Costa Rica and to determine the predominant nematode species in different soil texture classes. The most frequent nematodes in roots from Cartago were Meloidogyne (30\%), Globodera (33\%) and Pratylenchus (63\%). Pratylenchus and Globodera were also present in Zarcero. Pratylenchus was found in all textural classes of soil (clay loam, loam, loamy sand, sandy clay loam and sandy loam), whereas Meloidogyne was not present in loam, loamy sand and sandy, and Globodera was not found in clay loam. Globodera and Pratylenchus were found between 2500 and 3000 m.a.s.1., and Meloidogyne between 2000 and 2500 m.a.s.l. Molecular methods allowed the identification of M. incognita, M. hapla and G. pallida in potatoes. Currently, molecular tools and phylogenetic approaches are being used to identify the Pratylenchus species.

Effects of fluopyram on soybean cyst nematode resistance management under greenhouse conditions K. C. BRODERICK (1), C. Picinini (2), L. J. Giesler (3), (1) University of Nebraska-Lincoln, Lincoln, NE, USA; (2) Univeristy of Sao Paulo - Escola Superior de Agricultura Luiz de Queiroz, Piracicaba, BRAZIL; (3) Univ of Nebraska-Lincoln, Lincoln, NE, USA

Soybean cyst nematode (SCN, Heterodera glycines) is the most economically important soybean pathogen in the United States. Host resistance effectively controls SCN, however populations virulent to PI 88788 resistance are evolving, warranting additional controls options. The objectives of this study were: 1) to determine the effects of nematode seed treatments on SCN reproduction on different SCN resistance sources, and 2) to determine if seed treatments combined with host resistance could slow development of virulence to host resistance sources. Four seed treatments (clothianidin + Bacillus firmus, fluopyram, clothianidin + B. firmus with fluopyram, and a nontreated control) were compared on two resistant sources, PI 88788 and Peking. Treatments received a base seed treatment of penflufen, prothioconazole, and metalaxyl. Using a population virulent to PI 88788, eggs were serially passed for 3 generations on the same treatment and then a modified SCN-type tests was performed on each SCN population. Fluopyram significantly decreased $\mathrm{SCN}$ reproduction but there was not a significant difference between resistant sources $(\mathrm{p}=0.05)$. Fluopyram treatments significantly slowed development of virulence to PI $88788(\mathrm{p}=0.10)$, but this was not observed with virulence to Peking. These results suggest that seed treatments containing fluopyram could have additional benefits in the management of SCN resistance when paired with resistant varieties.

Etiology and management of sour rot in grapes

M. HALL (1), G. Loeb (2), W. F. Wilcox (3), (1) Cornell University, Ithaca, NY, USA; (2) Cornell Univ, Geneva, NY, USA; (3) School of Integrative Plant Science State Agr. Expt. Sta., Cornell University, Geneva, NY, USA

Sour rot is a disease complex affecting grape growers and winemakers worldwide, characterized by the oxidation of the berry skin, internal development of acetic acid and partnered with the presence of Drosophila fruit flies. We have shown that acetic acid production requires yeast to produce ethanol and bacteria to subsequently convert the ethanol to acetic acid through an oxidation reaction. We have characterized the microorganisms involved, determining that several yeast species (Saccharomyces spp., Hanseniaspora spp., and Pichia spp.) partnered with acetic acid bacteria (Gluconobacter spp. and Acetobacter spp.) can cause this reaction, but only in the presence of Drosophila spp. To investigate potential non-microbial contributions of Drosophila spp. to the complex, we produced axenic D. melanogaster eggs and reared larvae until axenic conditions, yielding adults devoid of gut or surface microbiota. Wounded berries exposed to the wild type flies for 8 days produced typical sour rot symptoms, but in order for symptom development to occur in those in the presence of axenic flies, co-inoculation with a yeast and acetic acid bacteria was required. In field trials conducted on cv. 'Vignoles' in 2013-16, both insecticide and antimicrobial treatments significantly reduced sour rot development. In 2015, untreated vines averaged $20.5 \%$ sour rot severity, and this was reduced by $73-81 \%$ on vines treated prophylactically post-veraison with weekly sprays containing a combination of the insecticide zeta-cypermethrin plus the antimicrobial potassium metabisulfite or hydrogen dioxide; severity was reduced by $49 \%$ on vines receiving only insecticide sprays. These trials further support the hypothesis that sour rot results from a complex of yeast, bacteria, and Drosophila spp. and that targeting these organisms can provide significant levels of control.

Almond trunk and scaffold canker diseases in California: Diagnosis, pathogenicity, and management L. A. HOLLAND (1), M. Nouri (2), N. Morris (1), M. Crespo (2), F. Trouillas (2), (1) Department of Plant Pathology, University of California, Davis, Davis, CA, USA; (2) Department of Plant Pathology, UC Kearney Ag. Research and Extension Center, Parlier, CA, USA 
Trunk and scaffold canker diseases (TSCD) of almond have become a major concern in the last decade in California. Symptoms go unnoticed during early stages of infection and become more visible as trees get older. Extensive gumming and dieback of scaffold branches can occur, eventually leading to tree death. Field diagnosis of TSCD remains challenging as symptom delineation among these diseases is not clear. Current management strategies against TSCD mostly rely on remedial surgery, cultural and prophylactic practices. However, the lack of chemical or biological control practices is becoming problematic. This study aims to identify the principal fungal pathogens associated with almond TSCD and investigate their incidence and management. In 2015 and 2016, sixty-five orchards with almond TSCD were surveyed. Isolations revealed numerous fungal species associated with cankers including Botryosphaeriaceae spp., Ceratocystis variospora, Cytospora spp., Phomopsis/Diaporthe spp., Diatrypaceae spp., and Collophora spp. A total of 292 isolates were identified. Botryosphaeriaceae spp. accounted for the largest group of pathogens. Ceratocystis infections were frequently encountered and C. variospora isolates from all counties sampled were genetically identical. New species of Cytospora were also found. Pathogenicity tests suggested species in the Botryosphaeriaceae are the most aggressive canker pathogens on almond. Additionally, C. variospora and two Cytospora species were also highly aggressive. In vitro assays and pruning wound protection field trials are ongoing in several orchards to test the efficacy of fungicides, biological control agents and sealants against TSCD pathogens.

Aspergillus flavus functional genomics: Toward enhancing host resistance to aflatoxin contamination under drought using biotechnology J. C. FOUNTAIN (1), G. Agarwal (1), P. Bajaj (2), M. Pandey (2), S. Nayak (3), R. C. Kemerait (4), R. Varshney (2), B. Guo (5), (1) University of Georgia, Tifton, GA, USA; (2) International Crop Research Institute for the Semi-Arid Tropics, Hyderabad, INDIA; (3) University of Agricultural Sciences, Dharwad, Dharwad, INDIA; (4) University of Georgia - Department of Plant Pathology, Tifton, GA, USA; (5) USDA ARS CPMRU, Tifton, GA, USA

The contamination of maize and peanut with aflatoxin during Aspergillus flavus infection is exacerbated by drought stress. This is correlated with the accumulation of reactive oxygen species (ROS) in host tissues. These ROS also stimulate the production of aflatoxin by $A$. flavus, which is postulated to provide fringe antioxidant benefits. In order to investigate the functional causes for isolate-to-isolate variation in oxidative stress responses and to characterize components pertinent to host resistance, 10 field isolates of $A$. flavus and A. parasiticus were used for whole genome re-sequencing (WGRS). Sequencing reads were aligned to the NRRL3357 reference genome with an average of 86.6X coverage for each isolate. Variant calling between the re-sequenced isolates and the reference genome found that toxigenic isolates exhibited fewer non-synonymous single nucleotide polymorphisms (SNPs) than atoxigenic isolates with averages of 22,601 and 34,294, respectively. Also, greater numbers of non-synonymous SNPs were observed than synonymous SNPs suggesting possible niche specialization in progress proportional to observed stress tolerance. Gene family variant enrichment analysis and variant influences on gene expression are under investigation. Understanding the factors influencing $A$. flavus stress responses and aflatoxin production will allow for targeted enhancement of host resistance through breeding, and the application of novel biotechnologies.

Comparative genomics of Aspergillus flavus $\mathrm{S}$ and $\mathrm{L}$ morphotypes yields insights into niche adaptation M. OHKURA (1), P. J. Cotty (2), M. Orbach (1), (1) University of Arizona, Tucson, AZ, USA; (2) USDA-ARS, University of Arizona, Tucson, AZ, USA

There are two distinct morphologies within Aspergillus flavus: the $\mathrm{S}$ morphotype produces numerous small sclerotia and lower numbers of conidia while the L morphotype produces fewer large sclerotia and abundant conidia. Isolates of the $\mathrm{S}$ morphotype consistently produce aflatoxin, whereas isolates of the $\mathrm{L}$ morphotype range from atoxigenic to highly toxigenic. The production of abundant sclerotia by the $\mathrm{S}$ morphotype suggests adaptation for longterm survival in the soil, whereas the production of abundant conidia by the L morphotype suggests adaptation for aerial dispersal to the phyllosphere. Selection pressure for aflatoxin production may be high in the soil favoring retention of toxin production, and low in the phyllosphere allowing atoxigenic isolates to survive. To develop hypotheses on differential niche adaption, genomes of the S and L morphotypes were compared to identify structural differences and genes unique to each morphotype. A $530 \mathrm{~kb}$ inversion was identified and its borders affect a secondary metabolite gene cluster and a cutinase gene. The $\mathrm{L}$ morphotype genomes contained 10 deletions relative to the $\mathrm{S}$ morphotype, including several secondary metabolite genes. Each morphotype has unique genes involved in carbon/nitrogen metabolism, secondary metabolism, and antimicrobial defense. These findings suggest the genomes of the two morphotypes differ beyond developmental genes, and may have diverged as they adapted to their respective niches.

Computational prediction of time-course subnetwork modules associated with histidine kinase activities in maize pathogen Fusarium verticillioides

M. KIM, W. B. Shim, Texas A\&M University, College Station, TX, USA

Fusarium verticillioides is a fungal pathogen causing maize ear rots worldwide, and maize contaminated with fumonisins poses human and animal health risks. There is a critical need to improve our understanding of the disease to develop effective control strategies. Recently, we developed computational methods to analyze large-scale RNA-Seq datasets and identify F. verticillioides genes as potential molecular targets for disrupting pathogenesis and reducing fumonisin contamination. This study demonstrates our effort to systematically investigate the role of histidine kinase (HK) genes during Fusarium ear rot. We performed network-based comparative analysis in a time-course manner to monitor differential HK gene activities in $F$. verticillioides on maize kernels compared to vegetative growth. We found that majority of HK genes are significantly activated with other genes at certain time points only. Meanwhile selected HK genes are significantly activated at multiple time points, but with closely correlated genes drastically changing over time. We identified HK genes associated with the osmotic-stress response signaling, a well-known function of HK, and show that the transcriptional subnetwork modules between HK two-component system and Hog MAP kinase cascade are correlated in a complex manner. This computational method allows us to advance the discovery of time-specific co-expression subnetwork modules associated with HK gene regulation and Fusarium ear rot pathogenesis.

Modeling complex associations among weather, deoxynivalenol contamination, and Fusarium head blight in wheat W. BUCKER MORAES (1), F. Dalla Lana (2), B. K. Baik (3), P. B. Schwarz (4), L. V. Madden (5), P. A. Paul (5), (1) The Ohio State University, Wooster, OH, USA; (2) Ohio State University, Columbus 43210, OH, USA; (3) United States Department of Agriculture, WOOSTER, OH, USA; (4) North Dakota State University, Fargo, ND, USA; (5) Ohio State Univ, Ohio Agricultural Research and Development Center, Dept of Plant Pathology, Wooster, OH, USA

Fusarium head blight (FHB), caused by Fusarium graminearum, is associated with wheat grain contamination with harmful mycotoxins such as deoxynivalenol (DON). Although FHB is a good indicator of DON, this relationship breaks down under certain weather conditions. One possible explanation for this could be the conversion of DON to DON-3-Glucoside (D3G), which is often missed by common DON testing methods. An experiment was conducted to investigate the effects of rainfall patterns on DON-D3G conversion in wheat grains. Separate replicate plots with different levels of FHB were subjected to one of six rainfall treatments: rainfall every day (Rain1); every other day (Rain2); two days with, two days without rainfall (Rain3); three days with, three days without rainfall (Rain4); four days with, five days without rainfall (Rain5); and no supplemental rainfall 
(check). There was a significant positive relationship between DON and D3G. Rain1 resulted in significantly higher mean D3G than the other treatments. Rain4 resulted in higher mean D3G than Rain2, Rain3, and Rain5. All rainfall treatments induced sprouting, as indicating by low falling number (FN). Rain 1 consistently had the lowest mean FN, whereas Rain4 resulted in significantly lower mean FN than the other intermittent rainfall treatments. There was a significant positive relationship between DON-D3G conversion (based on D3G/DON ratios) and sprouting. This study is the first to associate DON-D3G conversion to pre-harvest rainfall patterns and sprouting, and provides new information that is invaluable for understanding this complex disease-toxin system.

Casting a new die: Integrating novel biological insights and translational approaches to combat mycotoxin problems in maize J. B. RIDENOUR (1), W. D. Hawkins (1), B. Dhillon (1), J. E. Smith (1), Y. Ramegowda (1), W. B. Shim (2), C. P. Woloshuk (3), B. H. Bluhm (1), (1) University of Arkansas, Fayetteville, AR, USA; (2) Texas A\&M University, College Station, TX, USA; (3) Purdue University, West Lafayette, IN, USA

Mycotoxin contamination of maize (Zea mays) threatens food safety worldwide. Fumonisins, produced by the maize ear rot pathogen Fusarium verticillioides, are a group of mycotoxins linked to neural tube birth defects and esophageal cancer. Adequate resistance to fumonisin accumulation in maize has remained elusive despite the associated health risks. In this work, we sought to advance our understanding of how $F$. verticillioides senses and responds to the kernel environment and to integrate these findings into novel approaches to reduce fumonisins in maize. Through a combination of forward and reverse genetics, we have recently identified a number of novel fungal genes required for kernel colonization and/or fumonisin biosynthesis, including $U B L 1$, an E3 ubiquitin ligase that mediates the N-end rule proteolysis pathway, and $F U G 1$, a fungal-specific gene of unknown molecular function. To complement pathogen-driven target discovery, we developed an efficient strategy to evaluate fungal genes for potential mycotoxin control, wherein hairpin RNA (hpRNA) constructs were evaluated for suppression of target gene expression in the fungus prior to generating transgenic maize plants. Taken together, the lessons learned in F. verticillioides have uncovered novel insights into mycotoxin regulation and are expanding the translational tools available to mitigate the occurrence of fumonisins and other mycotoxins in maize.

Epidemiology and distribution of bacterial leaf streak of corn caused by Xanthomonas vasicola

T. HARTMAN (1), J. Harbour (1), B. Tharnish (1), J. Van Meter (2), T. A. Jackson-Ziems (1), (1) University of Nebraska-Lincoln, Lincoln, NE, USA; (2) Nebraska Department of Agriculture, Lincoln, NE, USA

In 2016, Xanthomonas vasicola, causal agent of bacterial leaf streak, was confirmed in Nebraska corn fields, the first detection in the United States. In 23 countries around the world, $X$. vasicola is known to cause disease on a wide range of hosts, most notably gumming disease of sugarcane. In 2016, a survey was conducted, primarily in Nebraska, to determine the distribution of the pathogen and to learn about agricultural practices that may favor disease development. To gather survey data, farmers, crop consultants, and other agribusiness cooperators were queried about their cropping practices. They were also asked to submit symptomatic leaf samples for pathogen isolation. A total of 409 samples and surveys were returned for analyses. $X$. vasicola was confirmed by PCR on bacterial colonies isolated from samples submitted from 51 Nebraska counties. Survey responses are being analyzed with classification and regression tree (CART) and the random forest algorithm. Results of virulence tests conducted on additional plant species will also be presented.

Understanding the recent outbreak of Dickeya dianthicola causing potato soft rot and blackleg in the United States

J. HAO (1), A. O. Charkowski (2), S. Johnson (3), G. A. Secor (4), (1) University of Maine, Orono, ME, USA; (2) Colorado State University, Fort Collins, CO, USA; (3) Univ of Maine Coop Ext, Presque Isle, ME, USA; (4) North Dakota State University, Fargo, ND, USA

An outbreak of Dickeya caused disease occurred in 2015 and 2016 in the Eastern US, and D. dianthicola has been determined to be the major causal agent. This problem continues to be a threat since then and $D$. dianthicola has been found in at least 23 states in the US. Furthermore, multiple Pectobacterium spp. are frequently found in blackleg and soft rot samples along with $D$. dianthicola. This pathogen complex causes significant economic losses throughout the season due to low emergence and necrotic stems during the growing season and rotted tubers in storage. Contaminated seed potato tubers are a major source of inoculum, but the bacteria can survive and spread on crops other than potatoes, and can survive in the environment, particularly in surface water. Pathogen detection by PCR from tuber stem ends or periderm is a primary tool to evaluate seed potato lots for Dickeya and test results are used to eliminate seed lots with high pathogen incidence from production. Unfortunately, most published detection primers failed when we attempted to validate them with field samples. Sanitation and proper handling of tubers at planting and storage can reduce disease spread. Five antibacterial products were tested to identify additional chemicals farmers could use for sanitation. Elite breeding lines were screened to identify resistant or tolerant lines. To better understand the outbreak, researchers are focused on strain identification, the effect of climate, as well as pathogen distribution, spread and biology. Findings such as where $D$. dianthicola resides on potato tubers and how it goes to dormant state will improve the efficiency of detection and elimination of pathogens.

Zebra chip, what we know and where are we headed

E. A. PIERSON, Texas A and M University, College Station, TX, USA

Texas A and M University, College Station, TX, USA

Outbreaks of Zebra Chip (ZC) on potatoes in the Americas and New Zealand arising in the 1990's and the rapid and devastating proliferation of Huanglongbing (HLB) on citrus elevated the recognition of 'Candidatus Liberibacter' pathogens. 'Ca. L. solanacearum' (CLso) is the causative agent of $\mathrm{ZC}$ and diseases on major solanaceous crops as well as carrot and celery and is transmitted by psyllids. The epidemiology and management of CLsoassociated diseases is complicated by different haplotypes of the pathogen and multiple, genetically variable psyllid vectors with different host ranges. Progress in understanding disease epidemiology and developing management strategies was facilitated by active interaction between researchers, industry, and producers. Management of potato production depends on aggressive psyllid control, albeit with few chemicals and developing resistance. Worldwide proliferation of CLso-associated diseases on current and new hosts will continue with vector range expansion. No host resistance to CLso has been discovered, though breeding for disease tolerance has met with some success. Biological control of insects, microbial agents with plant growthpromoting capabilities, and phage-based therapies targeting the pathogen are promising approaches to augment disease management. Gene silencing and CRISPR/Cas gene editing may yield insights and strategies to control insect populations and modulate host symptoms. Despite progress there is much to do.

Detection and characterization of Xanthomonas vasicola pv. vasculorum pv. nov. causing bacterial leaf streak of corn in the United States J. M. LANG (1), E. DuCharme (1), J. R. Ibarra (1), E. Luna (1), T. Hartman (2), K. Korus (3), J. Rascoe (4), M. C. Ortiz (1), T. A. Jackson-Ziems (2), K. D. Broders (1), J. E. Leach (1), (1) Colorado State University, Fort Collins, CO, USA; (2) University of Nebraska-Lincoln, Lincoln, NE, USA; (3) Alachua County Extension, University of Florida, Gainesville, FL, USA; (4) USDA-APHIS-PPQ-S\&T-CPHST, Beltsville, MD, USA 
Bacterial leaf streak of corn (Zea mays) recently reached epidemic levels in three corn-growing states, and was detected in another six states in the central United States. Xanthomonas vasicola was identified as the causal agent of this disease, however, the biology and taxonomy of this pathogen are not well understood. Multi-locus sequence alignment (MLSA) of six housekeeping genes and comparison of average nucleotide identity (ANI) from draft genome sequence confirmed phylogenetic relationships and classification of this bacterium relative to other Xanthomonas vasicola strains. X. vasicola strains from Nebraska and South Africa were highly virulent on corn and less virulent on sorghum or sugarcane, but caused water-soaking symptoms that are typical of $X$. vasicola infection on the leaves of all three hosts. Based on host range and phylogenetic comparison, we propose the taxonomic designation of this organism to $X$. vasicola pv. vasculorum pv. nov. Robust molecular diagnostic assays were developed that distinguish $X$. vasicola pv. vasculorum pv. nov. and X. vasicola pv. holcicola from each other and from other Xanthomonas spp.

The socioeconomic impact of emerging and re-emerging disease epidemics

A. O. CHARKOWSKI, Colorado State University, Fort Collins, CO, USA

The fundamentals of on-farm bacterial disease management in plants have not changed for most crops since the 1930s. Exclusion and sanitation are used in almost every crop. Plant resistance is sometime available and when appropriate, insect vector management can reduce disease spread. Since the 1930s, phytosanitary regulations on production and import of plant propagules have been used to manage the spread of bacterial plant pathogens via planting material. The impact in disease reduction of these regulations can take decades to detect and long term datasets that can be correlated with regulatory changes are only available for a few crops, such as seed potato. With these datasets, the cost of implementing these regulations can be estimated and compared to potential disease losses. Examples of the impact of regulation on management of Clavibacter, Ralstonia, Liberibacter, and Dickeya in potato production over the past 80 years will be detailed. The socioeconomic impacts of these disease in potato, a vegetatively propagated crop, will be compared to the impacts of diseases caused by these same bacterial genera in true seed crops. Potential unintended negative socioeconomic effects of regulations targeted to disease management, particularly as they impact small farms, will also be presented.

\section{Adapting disease forecasting models to climate change scenarios}

K. A. GARRETT (1), R. Choudhury (2), K. F. Andersen (3), (1) University of Florida, Gainesville, FL, USA; (2) University of Florida Plant Pathology Department, Gainesville, FL, USA; (3) Plant Pathology Department, Gainesville, FL, USA

Disease forecasting models can be an important component of climate change adaptation. However, climate change offers challenges for the construction and maintenance of disease forecasting models, which must not only address weather variability, but also underlying trends in weather. We developed a framework for evaluating the climate scenarios where forecasting models will become more or less useful. In general, forecasting models may be of little use in environments where the disease in question is extremely common or rare. Optimizing forecasting models may involve tracking where climate change is predicted to shift disease prevalence. The quality (skill) of models used for constructing weather indices for yield loss is also an important factor, along with the spatial heterogeneity of the environment in which the models are applied. Where climate change results in increased weather variability, this may also reduce the success of forecasting models. One aspect of this effect is the potential for more frequent weather conditions that fall outside those used to parameterize the model. The extent to which a forecasting model is mechanistic will help to determine whether it can be applied effectively in novel weather conditions. We discuss the types of ongoing modifications that can help to make forecasting models resilient under climate change, so that they can successfully contribute to climate change adaptation strategies.

\section{Adapting to water insecurity: Balancing reduced water use with root disease risk}

J. M. DEL CASTILLO MUNERA (1,2), B. Belayneh (2), J. Lea-Cox (2), C. L. Swett (3), (1) University of California, Davis, Davis, CA, USA; (2) University of Maryland, College Park, MD, USA; (3) Department of Plant Pathology, University of California - Davis, Davis, CA, USA

The agricultural sector consumes the highest percentage of available fresh water and, with climate change driving increased in water insecurity, agricultural demands are becoming unsustainable. Sensor-driven deficit irrigation networks use less water by allowing a mild crop stress, but may pose disease risks. The objectives of this study were to evaluate (i) effects of deficit irrigation (DI) on Phytophthora root disease in tomato and (ii) effects of DI on root disease in commercial greenhouse crops. When tomatoes inoculated with Phytophthora capsici were placed under saturated, mild deficit and severe deficit irrigation treatments, disease severity was significantly lower under the saturated and mild deficit treatment compared to severe deficit $(P=$ 0.025). The mild deficit deployed $18 \%$ less water than the saturated treatment; irrigation treatment did not affect growth of non-inoculated plants. There was no effect of minor deficit on Pythium root rot in commercially grown poinsettias. When poinsettias were inoculated with Pythium aphanidermatum, disease incidence was significantly lower under saturated and mild deficit conditions, compared to the severe deficit treatment $(P=0.05)$. These studies indicate that, although severe deficit increases risk of disease losses and should be avoided, minor deficit may not increase root disease risk and can reduce water usage, improving water security in agricultural systems.

How changes of annual soil temperature and moisture affect rhizosphere oomycete communities A. Rojas (1), R. L. Matthiesen (2), A. E. Robertson (3), K. E. Urrea (4), J. C. Rupe (4), M. CHILVERS (5), (1) Duke University, Durham, NC, USA; (2) Iowa State University, Ames, IA, USA; (3) Iowa State University, Department of Plant Pathology, Ames, IA, USA; (4) University of Arkansas, Fayetteville, AR, USA; (5) Michigan State University, East Lansing, MI, USA

Yield loss in the US alone due to seedling and root rot diseases caused by oomycete and fungal pathogens are estimated to be in the order of 100 million bushels for soybean and corn, respectively. Soil temperature fluctuations and precipitation pulses affect the severity of oomycete disease and the species responsible. Using multiple approaches, we demonstrate the impact of temperature on the oomycete species profile that cause disease and the interaction between these pathogens and fungicides as influenced by temperature. A culture-based survey of oomycetes from soybean across the US soybean belt demonstrated a significant shift in oomycete species between years with differing weather conditions. A follow up study using an amplicon sequencing approach, demonstrated that the oomycete "seed bank" differed by latitude/longitude but not by year. The influence of temperature on the recovered oomycete community profile was confirmed using controlled temperature baiting experiment and controlled temperature pathogenicity and virulence assays. In addition to the effect of temperature on species composition, fungicide sensitivity was also demonstrated to be affected by temperature regimes. The knowledge generated through these studies will aid in improved modelling of oomycete diseases and management through breeding resistance to appropriate species and improved targeting of chemical and biological seed treatments.

Presence of Ralstonia solanacearum cold virulent strains in the U.S. and mechanisms of virulence at low temperature A. M. BOCSANCZY (1), D. J. Norman (2), J. C. Huguet-Tapia (3), A. Mangravita-Novo (1), (1) University of Florida MREC, Apopka, FL, USA; (2) Univ of Florida MREC, Apopka, FL, USA; (3) University of Florida, Gainesville, FL, USA 
Climate change has a very diverse effect on different agricultural areas of the world. In southern United States, the consistent rise in temperature, longer planting periods, and extreme weather events are already favoring the introduction of tropical climate related diseases such as Bacterial Wilt caused by the bacterium Ralstonia solanacearum. We are documenting the increasing presence of strains introduced from the Caribbean that are capable of causing disease at lower temperatures than the usual tropical temperature range with the potential to further spread to northern states. The increase in temperature is also favoring the movement of tropical strains towards higher latitudes. This presence not only can increase the potential for epidemics in economical important crops such as tomato, and tobacco but also can increase the risk of acquiring low temperature virulence and of extending host ranges to include novel temperate climate hosts such as blueberry. It is very important to understand virulence at low temperature and its mechanisms. In our lab we used comparative proteomics, and genomics approaches to understand at molecular level this capability which until recently was assigned to only a monophyletic group of $R$. solanacearum [R3B2] which is not present in the United States. We are also studying Type 3 effectors that can be horizontally transferred between diverse strains extending their host range to include temperate climate plant crops.

How to use outreach to help farmers adapt to climate change

A. E. ROBERTSON, J. Arbuckle, Jr., Iowa State University, Ames, IA, USA

Outreach shares information with communities to enable them to adapt or mitigate challenging situations. Understanding the community with whom the information is shared is important to ensure the outreach is successful. Within the past few years, considerable research has been done in the Corn Belt through surveys of farmers, extension educators, and private crop advisors to understand their beliefs and attitudes regarding climate change and potential adaptive management strategies. The data suggest that due to political sensitivity surrounding climate change and its causes, direct outreach to farmers and advisors should focus on the impacts of climate change: weather extremes and associated problems such as pests and disease. Most farmers have experienced extreme weather events that impacted their production, thus outreach that addresses adaptation to extreme weather events and related impacts resonate with farmers. Moreover, research suggested that farmers are generally confident in their adaptation skills and are more responsive to outreach focused on ways to adapt to variable weather rather than discussion of climate change. The research also showed that extension is the most trusted source of information on climate change and dealing with extreme weather, among both farmers and advisors, and this should be capitalized on. Today, farmers are likely to go to private advisors, since there are fewer extension educators. Private advisors reported they depend on extension for reliable information on climate change. Thus, a potentially effective way to help farmers adapt to climate change is to foster relationships between extension and private industry and "train the trainer".

Design and teaching of plant pathology and biology labs

D. ROUSE, University of Wisconsin-Madison, Madison, WI, USA

Hands-on experiences that can be achieved in a teaching laboratory are an important means of learning in the biological sciences. Different kinds of laboratory experiences illustrate the range of possibilities and the kind of learning on Blume's taxonomy that may be achieved in the laboratory. There are activities that simply allow students to see the pathogens and diseases discussed in lecture first hand, for example make a wet mount and see an oospore inside an infected root. Students may also conduct experiments designed to illustrate a concept, such as inoculate viruses onto indicator plants. Students may engage in completely open-ended inquiry activities where they get to practice the process of science and develop their own ideas about plant pathology concepts. Ultimately there is the classroom undergraduate research experience (CURE) model. All of these have their place, and a mix of different kinds of activities may be best. Nevertheless, among education researchers there is much discussion about what is best, and there is a strong theme currently to drive as far toward inquiry based activities as possible. The importance of the teaching laboratory for experiencing and learning how to work in small groups should also not be underestimated.

Less watching, more doing: Hands-on activities to enhance undergraduate courses B. SPAKES RICHTER, University of Florida, Gainesville, FL, USA

Educational research has consistently reinforced the concept that we learn best by doing, rather than by watching, and results of a recent APS research survey indicate that employer satisfaction with BS-degreed employees is marred by frustration with deficiencies in hands-on skills. Yet the lecture format remains the most common mode for teaching. Lectures are efficient for delivering information to large groups, they are familiar and comfortable for both professors and students, and they require less preparation than most experiential learning modes. Classroom design and time periods often favor the lecture format, and many of us struggle to provide meaningful content interactions in short time frames, with no lab facilities, to students whose lectern-facing chairs are literally bolted to the floor. Yet, even in the most inconducive of settings, there are ways to incorporate hands-on activities. This presentation will share results of employer surveys, identifying particular skills that hiring managers and supervisors would like to see better developed among undergraduate students, and will explore ways to address these deficits and incorporate hands-on learning in non-laboratory classes.

Design and delivery of immersive online labs

D. SHEW, A. Koehler, A. Mendoza-Moran, North Carolina State University, Raleigh, NC, USA

Labs and lab-based activities are vitally important to teaching an effective undergraduate Plant Pathology course. Well designed labs build the connections between conceptual/fact-based learning and application of that knowledge to real-world scenarios. Interactive labs, whether face-to-face or online, provide needed opportunities to complete activities that allow students to achieve outcome-based learning objectives that cannot be met solely in lecture-based classrooms. To be effective, online labs must employ methods that effectively reach a diverse student population, with the goal of creating a learning experience that is as similar as possible to in-class labs. In this presentation, we will discuss how a variety of presentation styles and technologies such as interactive web platforms and gaming can be used to enrich the online lab experience for undergraduates in an Introductory Plant Pathology course. Emphasis is placed on how we help students achieve an enhanced understanding of the fundamental skills of plant pathology and experimental design.

Molecular biology-based lab methods using plant nematodes

K. LAMBERT, University of Illinois, Urbana, IL, USA

The identification of plant parasitic nematodes in a laboratory class setting can be challenging. Often high-resolution microscopic equipment required for careful nematode observations are not available. While counter intuitive, the use of molecular biological techniques in nematode identification is often simpler, more accurate and offers students the opportunity to combine classical nematology techniques with more modern laboratory methods. By mixing a combination of "hands-on" nematode wrangling, micro-scale DNA extraction and computational analysis of nematode DNA sequences, the often tedious task of plant nematode identification can become a highly interactive experience for undergraduate plant pathology students. To 
successfully use molecular methods in identifying plant nematodes, access to a thermocycler and basic agarose gel electrophoresis equipment, common in many research laboratories, is necessary. Having DNA sequence files for student practice is also useful. For molecular methods to function smoothly in a plant pathology laboratory, it is critical that all methods are as streamlined as possible. Simple single-tube DNA extractions and PCR reactions are conducted by the students and then, while the thermocyclers are running, a discussion on how the data is analyzed is conducted. Students are provided with a list of web sites that host free bioinformatics tools so they can analyze sequence data and conduct homework assignments. The use of locally extracted nematodes from student-collected samples can provide a useful survey of common plant nematodes in the area and raise awareness of nematode ecology, which can feedback in to the lecture portion of the class.

Distinct E3 ligases regulate the turnover of individual components of paired typical NLR immune receptors O. Dong (1), F. Xu (1), K. Ao (1), X. LI (2), (1) University of British Columbia, Vancouver, CANADA; (2) University of British Columbia, Vancouver, BC, CANADA

In plants, immunity mediated by nucleotide-binding leucine-rich repeat (NLR) immune receptors often requires the formation of NLR hetero-pairs. As the partner has not yet been identified for the Arabidopsis NLR SUPRESSOR OF NPR1, CONSTITUTIVE 1 (SNC1), a reverse genetic screen was undertaken and the NLRs SIDEKICK SNC1 1 (SIKIC1), SIKIC2, and SIKIC3 were found to be redundantly required for SNC1-mediated defense. IPMS analyses indicated that the SIKICs indeed interact with SNC1 as typical NLR pairs. Furthermore, the protein levels of the SIKICs are regulated by either MUTANT, SNC1-ENHANCING 1 (MUSE1) or MUSE2, two previously uncharacterized redundant E3 ubiquitin ligases that were identified from a genetic screen for $s n c 1$ enhancers. As SNC1 accumulation is regulated by the E3 ligase SCF ${ }^{\mathrm{CPR} 1}$, this report provides the first evidence that the homeostasis of individual components of a typical NLR pair are subject to differential regulation via ubiquitin-mediated protein degradation.

Positive and negative regulation of the NLR immune receptor Piz-t in rice

G. L. WANG, The Ohio State University, Columbus, OH, USA

Use of host resistance is the most effective method to control the devastating rice blast disease, caused by hemibiotrophic fungal pathogen Magnaporthe oryzae. However, the resistance mechanism to the pathogen has not been fully understood. We used the AvrPiz-t-Piz-t pair as a model to elucidate the molecular mechanism of rice immunity against $M$. oryzae. Using AvrPiz-t as the bait in yeast two-hybrid screens, we identified 12 AvrPiz-t-interacting proteins (APIPs) and characterized the function of APIP5, APIP6, APIP10 and APIP12 in rice immunity. We found that AvrPiz-t suppresses the ligase activity of both E3 ligases APIP6 and APIP10 and targets both proteins for degradation. At the same time, both E3 ligases ubiquitinate AvrPiz-t that leads to degradation. Genetic analysis showed that APIP6, APIP10 and APIP12 are positive regulators of PAMP-triggered immunity (PTI). Interestingly, APIP10 is also a negative regulator of the nucleotide-binding domain and leucine-rich repeat (NLR) receptor Piz-t. Silencing of $A P I P 10$ leads to induction of the Piz-t protein and cell death in transgenic rice. We also found that the transcription factor APIP5 is essential for the accumulation of the Piz-t protein in rice. In return, Piz-t interacts with and stabilizes APIP5 to prevent necrotrophy at the late infection stage. These results demonstrate that the Piz-t protein level is negatively and positively regulated by an E3 ligase and a transcription factor, respectively, in rice.

Barley Bait-and-Switch: A receptor kinase bait switches on programmed cell death in response to Puccinia graminis R. S. BRUEGGEMAN, S. Solanki, R. Sharma Poudel, J. Richards, G. Ameen, North Dakota State University, Fargo, ND, USA

The barley NLR genes, Rpg5 and HvRgal, are required together for rpg4-mediated resistance to P. graminis f. sp. tritici (Pgt), wheat stem rust, and have the head-to-head genome architecture of integrated decoy (ID) resistance mechanisms. The ID hypothesis explains why one NLR partner contains an atypical ID domain that mimics a pathogen's virulence effector target. Once these host effector targets are fused to NLR receptors they function as IDs that recognize the presence of the pathogen switching on defense responses. Alleles of Rpg 5 contain unique C-terminal IDs, with the resistance allele having a protein kinase (PK) ID and susceptible alleles containing a protein phosphatase 2C (PP2C) ID. The Rpg5-PK ID progenitor, HvApk1b, is the Arabidopsis AtAPK1b ortholog that is involved in stomatal aperture opening. Laser Capture Microdissection followed by qPCR determined that HvApk $1 \mathrm{~b}$ is also highly expressed in barley stomata. Thus, we hypothesize that the Pgt effector, Avr-4/5, manipulates HvApk1b during the infection process facilitating pathogen entry through otherwise closed stomata. Barley counter evolved the Rpg5-PK ID immunity receptor via duplication and translocation of the HvAPK1b target protein. Thus, Pgt evolved a virulence effector that facilitates stomata entry, yet, barley counter evolved a "bait" that betrays the pathogen switching on defense responses resulting in resistance to diverse Puccinia graminis formae speciales and races including TTKSK.

An atypical pair Mi-1.2 and SERK1 regulate aphid resistance in tomato

I. KALOSHIAN, University of California, Riverside, CA, USA

The tomato (Solanum lycopersicum) Mi-1.2 gene, encodes a coiled-coil nucleotide-binding leucine-rich repeat protein, confers resistance to three species of root-knot nematodes (Meloidogyne spp.) and to three phloem-feeding insects including potato aphid (Macrosiphum euphorbiae). To date, no nematode or insect effectors recognized by Mi-1.2 have been identified. However, we have shown that potato aphid protein extracts and potato aphid saliva induce the Mi-1.2 defense marker WRKY72b, indicating that both protein extracts and saliva contain the Mi-1.2 cognate effector. We have also discovered that Mi-1.2-mediated resistance to potato aphid, and not to root-knot nematodes, requires the Somatic Embryogenesis Receptor Kinase 1 (SERK1). The tomato SERK1 belongs to a gene family of three transmembrane receptor kinases known for their roles in pattern-triggered immunity. In this presentation, I will discuss our understanding how Mi-1.2 and SERK1 interact to induce immunity against potato aphids and the subcellular compartmentalization of Mi-1.2 to achieve resistance.

Using decoys to expand the recognition specificity of a plant disease resistance protein M. HELM, R. Innes, Indiana University, Bloomington, IN, USA

Genetic-based disease resistance is the most effective and environmentally sustainable approach to protecting crops from disease. Although significant progress has been made with respect to understanding the mechanistic basis of plant-pathogen interactions, a remaining challenge is to expand the recognition specificity of plant resistance $(R)$ proteins to confer entirely new specificities. We recently reported a novel approach for expanding the recognition specificity of an Arabidopsis $R$ protein by generating 'decoy' proteins that function as substrates for pathogen proteases. This strategy is based on the observation that modifying the protease cleavage site within Arabidopsis PBS1, a substrate of the AvrPphB cysteine protease, expands the recognition specificity of the Arabidopsis RPS5 immune response pathway. Thus, the specificity of RPS5 can be changed simply by altering the protease cleavage sequence within PBS1. We are now using this technology to engineer resistance in soybean (Glycine max) to Soybean Mosaic Virus (SMV) based on the recognition of the viral protease by a PBS1 'decoy' protein. Soybean encodes three co-orthologs of PBS1, and all three can be cleaved by 
AvrPphB. Furthermore, we show soybean recognizes AvrPphB, thus soybean likely contains an $R$ protein that detects PBS1 cleavage. We hypothesize that we will be able to engineer resistance to SMV by introducing a cleavage site recognized by the SMV protease into a soybean PBS1 ortholog. Transfer of an NLR gene from pigeonpea into soybean confers resistance to Asian soybean rust

P. VAN ESSE (1), C. Kawashima (1), J. Jones (1), S. Brommonschenkel (2), (1) The Sainsbury Laboratory, Norwich, UNITED KINGDOM; (2) Universidade Federal de Viçosa, Viçosa, BRAZIL

The fungus Phakopsora pachyrhizi is the causal agent of Asian soybean rust (ASR). In Brazil, the second largest producer of soybean in the world, the direct and indirect losses incurred by this pathogen are estimated at approximately 2 Billion US\$ per year. Since there are currently no commercial soybean cultivars that have durable resistance against P. pachyrhizi, frequent fungicide applications are the way to control the disease. Genetic resistance is highly desirable given the high cost to growers and the environmental impact of current ASR control strategies. Eight major loci for resistance against the disease have been identified, however none of the causal genes have been cloned. In addition, many of these loci have been introduced into commercial soybean cultivars individually. As a consequence, P. pachyrhizi isolates that have overcome these introduced loci can be readily identified in the field. We have cloned a P. pachyrhizi resistance gene from pigeonpea (Cajanus cajan) and named it CcRpp1 for Cajanus cajan Resistance against Phakopsora pachyrhizi 1. The CcRpp1 gene confers full resistance to P. pachyrhizi when introduced into soybean. Our findings show that legume species related to soybean such as pigeonpea, cowpea, common bean and others could provide a valuable and diverse pool of resistance traits for crop improvement.

Blippity BLOPs: Goals, information, uncertainty, and trust in Extension adoption problems N. MCROBERTS, University of California-Davis, Davis, CA, USA

Extension problems in agriculture are Bi-level Optimization Problems (BLOPs) in which actors (i.e. extension agents and farmers) operating at two different scales have overlapping but not identical goals. Standard economic approaches for optimizing goals routinely fail to work for BLOPs resulting in economic inefficiency and social costs. Newer methods for solving BLOPs point to the key roles that information flow, uncertainty, and trust among actors within and between scales play in the likelihood of satisfactory outcomes. Even without formal quantitative analysis, framing extension problems as BLOPs helps us to see these points and develop ways to incorporate them into extension practice. Many of the issues involved in achieving satisfactory outcomes can also be considered from the social network perspective, and by considering the ways in which the study of BLOPs might be undertaken we begin to characterize the analytical toolkit for future extension scientists and the means by which extension can be revitalized and given higher priority by policy makers.

Maintaining relevance and impact in food, feed, \& fiber security: Opportunities for the extension service K. A. EVERSOLE, K. J. Owens, Eversole Associates, Bethesda, MD, USA

US agriculture today is vastly different from that which existed throughout the country in 1914, the year that the extension service was formalized. Into the 1980s, extension was a primary informal source for agricultural knowledge for farmers of all sizes. Today, however, many farmers, especially those farming larger tracts of land, hire crop consultants. In at least one state, less than $12 \%$ of farmers seek assistance from extension agents. While part of this is due to the move to significant technological changes in farming, a good part is due to decreased funding for extension over the past few decades that resulted in fewer and fewer agricultural extension agents. Legislators determine the relevance and impact of services, such as extension, that are supported with state and Federal funding; can they be convinced that extension remains important? Some argue that knowledge is at the fingertips of anyone with a computer or access to a library so extension is no longer relevant. How can this be countered? What opportunities may exist as agriculture moves into a digital farming? How does extension fit within the phytobiomes vision? Methods of indicating impact to legislators and concrete opportunities for extension in the agriculture of the future will be presented. 